\title{
ARTICLE
}

\section{Elevated levels of Bcl-3 inhibits Treg development and function resulting in spontaneous colitis}

Sonja Reißig1, Yilang Tang ${ }^{1}$, Alexei Nikolaev¹, Katharina Gerlach², Christine Wolf ${ }^{3}$, Kathrin Davari ${ }^{3}$, Christian Gallus ${ }^{3}$, Joumana Masri ${ }^{1}$, Ilgiz A. Mufazalov ${ }^{1}$, Markus F. Neurath², F. Thomas Wunderlich ${ }^{4}$, Jörn M. Schattenberg ${ }^{5}$, Peter R. Galle ${ }^{5}$, Benno Weigmann ${ }^{2}$, Ari Waisman ${ }^{1, \star}$, Elke Glasmacher ${ }^{3, \star}$ \& Nadine Hövelmeyer ${ }^{1, \star}$

$\mathrm{Bcl}-3$ is an atypical NF- $\kappa \mathrm{B}$ family member that regulates NF- $\mathrm{B}$-dependent gene expression in effector T cells, but a cell-intrinsic function in regulatory $\mathrm{T}$ (Treg) cells and colitis is not clear. Here we show that $\mathrm{Bcl}-3$ expression levels in colonic $\mathrm{T}$ cells correlate with disease manifestation in patients with inflammatory bowel disease. Mice with T-cell-specific overexpression of $\mathrm{Bcl}-3$ develop severe colitis that can be attributed to defective Treg cell development and function, leading to the infiltration of immune cells such as pro-inflammatory $\gamma \delta$ T cells, but not $\alpha \beta$ T cells. In Treg cells, Bcl-3 associates directly with NF- $\kappa B$ p50 to inhibit DNA binding of p50/p50 and p50/p65 NF- $\kappa B$ dimers, thereby regulating NF- $\mathrm{B}$-mediated gene expression. This study thus reveals intrinsic functions of $\mathrm{Bcl}-3$ in Treg cells, identifies Bcl-3 as a potential prognostic marker for colitis and illustrates the mechanism by which $\mathrm{Bcl}-3$ regulates NF- $\mathrm{B}$ activity in Tregs to prevent colitis.

\footnotetext{
${ }^{1}$ Institute for Molecular Medicine, University Medical Center of the Johannes Gutenberg, University of Mainz, Obere Zahlbarer Str 67, 55131 Mainz, Germany ${ }^{2}$ Department of Medicine I, University Erlangen-Nürnberg, Research Campus, 91052 Erlangen, Germany. ${ }^{3}$ Helmholtz Zentrum München, Institute of Diabetes and Obesity (IDO), German Center for Diabetes Research (DZD), 85764 München-Neuherberg, Germany. ${ }^{4}$ Max Planck Institute for Metabolism Research, CECAD, CMMC, Institute for Genetics, 50931 Cologne, Germany. ${ }^{5}$ Department of Internal Medicine I, University Medical Center of the Johannes Gutenberg, University of Mainz, 55131 Mainz, Germany. * These authors contributed equally to this work. Correspondence and requests for materials should be addressed to N.H. (email: hoevelme@uni-mainz.de) or to S.R. (email: reissig@uni-mainz.de).
} 
T he mucosal immune system of the gastrointestinal tract mediates immune protection against foreign pathogens and simultaneously conveys tolerance to microbes in the gut. Failure to tolerate microbial antigens can result in inflammatory bowel disease (IBD), which includes Crohn's disease (CD) and ulcerative colitis (UC). The pathological process of both CD and UC involves cycles of inflammation, ulceration and subsequent regeneration of the intestinal mucosa ${ }^{1}$. CD is classically considered as a $\mathrm{T}_{\mathrm{H}} 1$-mediated disease, due to the predominance of interferon- $\gamma\left(\right.$ IFN- $\gamma$ )-producing CD4 ${ }^{+} \mathrm{T}$ cells in the mucosa ${ }^{2}$, whereas UC is characterized by infiltrating $\mathrm{T}_{\mathrm{H}} 2$ cells and the production of interleukin (IL)-5 (ref. 3). $\gamma \delta \mathrm{T}$ cells, which can secrete high levels of the pro-inflammatory cytokine IL-17A in the gut $^{4}$, have important functions in the pathogenesis of $\mathrm{IBD}^{5-7}$.

Regulatory $\mathrm{T}$ cells (Tregs) are essential for the maintenance of gut immune homeostasis, owing to their function as suppressors of cytokine production in $\mathrm{T}_{\mathrm{H}} 1$ and $\mathrm{T}_{\mathrm{H}} 2$ cells ${ }^{4,8,9}$. Moreover, Treg cells are important mediators of tolerance in the intestine and various studies have linked defects in Treg cell development or function to the onset of $\mathrm{IBD}^{10,11}$. Even though the contribution of Treg cells in the prevention of IBD is well-appreciated, the molecular factors regulating the functionality of Treg cells during IBD are still not entirely characterized.

The nuclear factor- $\kappa \mathrm{B}(\mathrm{NF}-\kappa \mathrm{B})$ transcription factor family is composed of five members: RelA (p65), RelB, c-Rel, p50

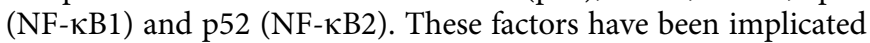
in the development and function of natural Treg (nTreg) cells, which develop in the thymus, as well as inducible Treg (iTreg) cells, which are derived from naive $\mathrm{CD} 4{ }^{+} \mathrm{T}$ cells after antigenic stimulation in peripheral tissues such as the gut ${ }^{12-15}$. Indeed, mice lacking NF- $\mathrm{KB}$ members such as p50, c-Rel and p65 have impaired Treg cell development ${ }^{15-17}$. Furthermore, in mice with $\mathrm{T}$-cell-specific transgenic expression of an inhibitors of $\kappa \mathrm{B}$ (I $\mathrm{KB}$ ) super-repressor, the number of $\mathrm{CD}_{4}{ }^{+} \mathrm{Foxp} 3^{+}$Treg cells correlates with NF- $\kappa B$ activity ${ }^{14}$. Nevertheless, although mice lacking p50, c-Rel and p65 have defective Treg cell development ${ }^{15-17}$, only mice lacking p65 develop signs of autoimmunity ${ }^{17}$, leaving an open question as to how NF- $\kappa B$ activity modulates Treg cell functionality to prevent the development of autoimmunity.

NF- $\kappa \mathrm{B}$ activity is regulated by members of the classical IкB protein family, including $І \kappa B \alpha$, I $\mathrm{B} \beta$ and $І \kappa B \varepsilon$, as well as p105/NF- $\kappa B 1$ and $\mathrm{p} 100 / \mathrm{NF}-\kappa \mathrm{B} 2$ precursors, whereas the atypical

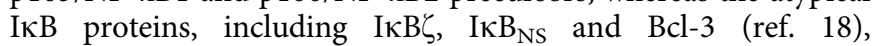
bind directly to NF- $\kappa B$ members in the nucleus and modulate $\mathrm{NF}-\kappa \mathrm{B}$-mediated gene expression. Bcl-3, originally identified as a proto-oncogene in a subgroup of B-cell leukaemia, enters the nucleus and associates selectively with DNA-bound NF- $\mathrm{KB}$ p50 or p52 homodimers to regulate NF- $\mathrm{\kappa B}$-dependent gene transcription. Bcl-3 was shown to enhance NF- $\mathrm{\kappa B}$-mediated transactivation by acting as a coactivator for $\mathrm{p} 50$ and $\mathrm{p} 52$ dimers. Further studies have shown that Bcl-3 is also able to inhibit NF$\kappa \mathrm{B}$-mediated transactivation by binding to p50 homodimers. The mode of Bcl-3 action, whether inhibitory or activating, further depends on the cell type investigated ${ }^{19-24}$. Studies using Bcl-3-deficient mice underline the importance of Bcl-3 in effective adaptive and innate immune responses against pathogens, in central tolerance and the prevention of autoimmune diseases, as well as in effector T-cell plasticity ${ }^{25-27}$. Moreover, Bcl-3 regulates intestinal epithelial cell proliferation and was shown to be essential for the induction of dextran sulfate sodiuminduced colitis ${ }^{28,29}$. Although these studies indicate a possible involvement of Bcl-3 in the regulation of effector $\mathrm{T}$ cells and gut immune homeostasis, the exact functions of Bcl-3 in Treg cells and IBD have not been reported.
In this study, we demonstrate that Bcl-3 is important for the maintenance of Treg cell function and the prevention of spontaneous colitis. Patient data show that Bcl-3 expression levels correlate with disease severity. In line with this, mice that overexpress Bcl-3 in T cells develop severe spontaneous colitis, which is not mediated by effector $\mathrm{T}$ cells but instead is caused by impaired Treg cell function resulting from altered NF- $\kappa B$ activity via cell-intrinsic regulation by Bcl-3. In Treg cells, Bcl-3 interacts with p50 and inhibits p50 DNA binding, and thereby alters the

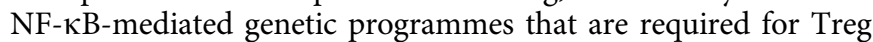
cell development and function. Thus, our study highlights the necessity to monitor Bcl-3 expression in both $\mathrm{CD}$ and $\mathrm{UC}$, and implicates Bcl-3 as a potential therapeutic target in IBD.

\section{Results}

Bcl-3 expression levels are increased in patients with IBD. To study a potential role of Bcl-3 in the pathogenesis of human IBD, we used immunohistochemistry to examine Bcl-3 expression levels in colons of patients suffering from either CD or UC. This staining revealed that $\mathrm{CD}$ and UC patients had massive infiltration of $\mathrm{Bcl}-3^{+}$cells in the lamina propria (LP), whereas control groups displayed only few Bcl-3 expressing cells within this area (Fig. 1a). Accordingly, quantitative reverse transcriptase-PCR (RT-PCR) analysis using RNA isolated from colons of patients with active $\mathrm{CD}$ or UC showed significantly increased levels of Bcl-3 expression compared with controls (Fig. 1b). To investigate specifically which cells express Bcl-3, immunohistochemistry from colon cross-sections of patients with $\mathrm{CD}$ and UC was performed. This analysis revealed increased numbers of $\mathrm{CD} 4^{+}$ $\mathrm{T}$ cells in the inflamed colon of both $\mathrm{CD}$, as well as UC patients compared with healthy patients (Fig. 1c). Indeed, we could show that in most regions, the majority of infiltrating $\mathrm{CD}^{+} \mathrm{T}$ cells was positive for Bcl-3 expression (Fig. 1c). Furthermore, we isolated LP T cells from UC and control patients and analysed the expression of Bcl-3 by western blotting. We observed that patients with UC expressed increased protein levels of Bcl-3 compared with control patients (Fig. 1d). Together, these data illustrate a direct correlation between Bcl-3-expressing $\mathrm{CD} 4{ }^{+} \mathrm{T}$ cells and the pathogenesis of IBD.

Bcl-3 ${ }^{\mathrm{TOE}}$ mice develop intestinal inflammation. To evaluate the functional role of increased Bcl-3 expression in $\mathrm{T}$ cells in the pathogenesis of IBD, we used a mouse model in which Bcl-3 and enhanced green fluorescent protein (eGFP) are expressed upon Cre-mediated recombination of a loxP flanked transcriptional STOP cassette ${ }^{30}$. These mice were crossed to the CD4-Cre mouse strain to obtain mice, termed $\mathrm{Bcl}-3^{\mathrm{TOE}}$, that specifically overexpress $\mathrm{Bcl}-3$ in all mature $\alpha \beta \mathrm{T}$ cells including Treg cells. Western blot analysis of purified $\mathrm{CD} 4^{+} \mathrm{T}$ cells of Bcl-3 ${ }^{\mathrm{TOE}}$ mice confirmed higher expression of $\mathrm{Bcl}-3$ compared with control $\mathrm{T}$ cells (Fig. 2a). Starting at 8 weeks of age, $\mathrm{Bcl}-3^{\mathrm{TOE}}$ mice suffered from severe diarrhoea and rectal prolapse (Fig. 2b, left). As the development of a rectal prolapse is a predisposition for colonic inflammation, those mice were examined by mini-endoscopy. We found that $\mathrm{Bcl}-3^{\mathrm{TOE}}$ mice spontaneously developed severe intestinal inflammation, as indicated by a significantly higher clinical score of colitis (Fig. 2b right and Fig. 2c), with an incidence of $>90 \%$. In addition, macroscopic examination of the intestine showed severe pancolitis affecting all parts of the colon distal from the caecum (Fig. 2d). Furthermore, histological haematoxylin and eosin analysis revealed a dramatic infiltration of immune cells into the colon of $\mathrm{Bcl}-3^{\mathrm{TOE}}$ mice (Fig. 2e). As T-cell-specific Bcl-3 overexpression drives the development of a strong colonic inflammation similar to the histopathology observed in patients with IBD, we further characterized the colitis 
a
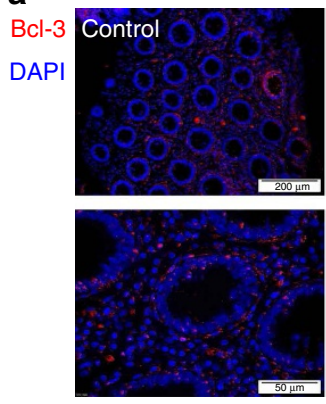

C
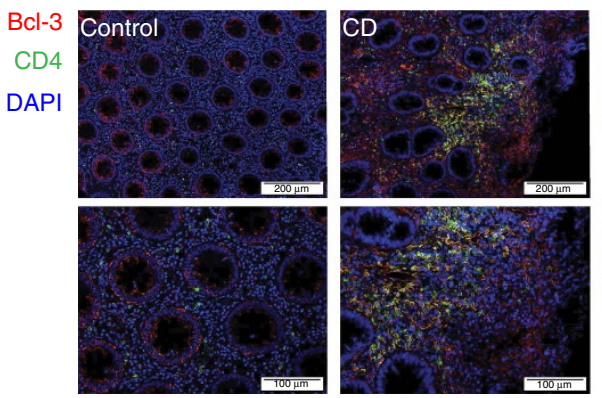

d
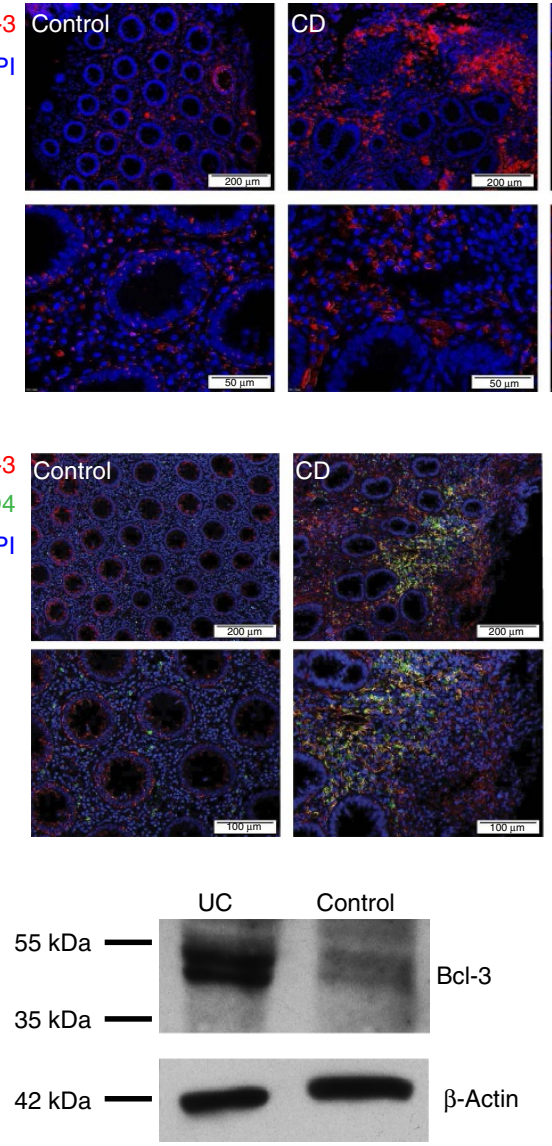

Actin b
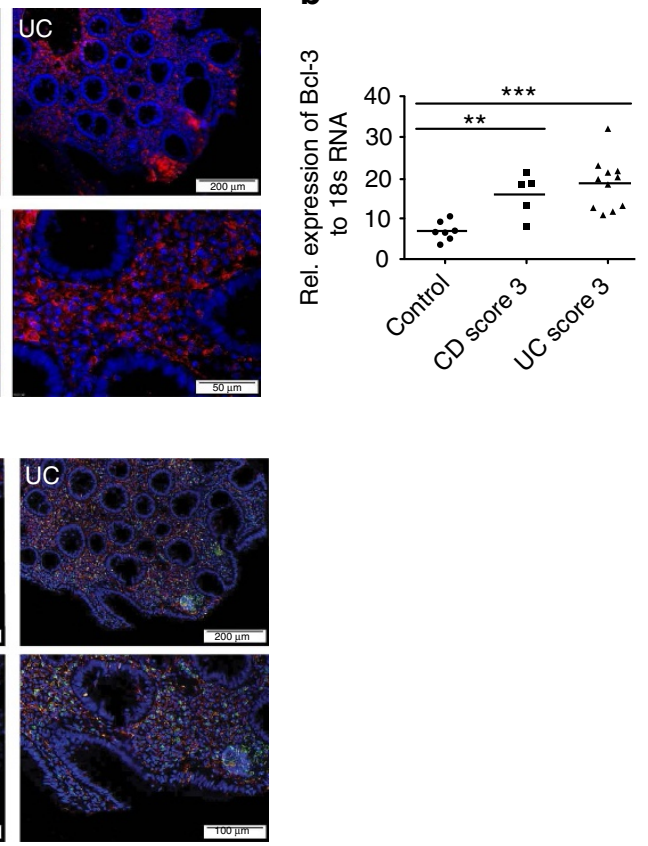

Figure 1 | Increased Bcl-3 expression levels in colons of IBD patients. (a) Representative picture of immunohistochemistry of human colonic tissue from control $(n=3), C D(n=3)$ and UC $(n=3)$ patients stained with Bcl-3-specific antibody (red). Nuclei were counterstained with Hoechst 3342 (blue). Scale bars, $200 \mu \mathrm{m}$ (upper panel) and $50 \mu \mathrm{m}$ (lower panel). (b) Quantitative real-time PCR analysis of Bcl-3 mRNA expression in colons from control ( $n=7$ ), CD patients $(n=5)$ and UC patients $(n=7)$. Results are presented as expression relative to $18 \mathrm{~S}$ rRNA. Each symbol represents one individual patient. Clinical score: $1=$ mild, $2=$ middle and $3=$ high. Data are represented as mean \pm s.e.m. ${ }^{\star \star \star} P<0.001$ and ${ }^{\star \star} P<0.01$ (analysis of variance (ANOVA)).

(c) Representative picture of immunohistochemistry of human colonic tissue from control $(n=3), \mathrm{CD}(n=3)$ and UC ( $n=3)$ patients stained for CD4 (green) and Bcl-3 (red). Nuclei were counterstained with Hoechst 3342 (blue). Scale bars, $200 \mu \mathrm{m}$ (upper panel) and $100 \mu \mathrm{m}$ (lower panel).

(d) Western blot analysis of $\mathrm{Bcl}-3$ expression in LP T-cell lysates isolated from human colonic tissue of one control and UC patient $(n=1)$. Actin was used as loading control.

phenotype in these mice and examined gene expression of different pro-inflammatory cytokines. Along with increased levels of Bcl3 transcript, expression of Il6, Ill7a, Tnfa and Ifng were significantly elevated in the colons of $\mathrm{Bcl}-3^{\mathrm{TOE}}$ mice compared with littermate controls (Fig. 2f), whereas expression of Ill0 was unaffected (Fig. 2f). Next, we performed immunohistochemistry of cellular infiltrates within the mucosa of $\mathrm{Bcl}-3^{\mathrm{TOE}}$ mice. We found increased numbers of infiltrating $\mathrm{CD} 4^{+} \mathrm{T}$ cells, $\mathrm{CD} 11 \mathrm{c}^{+}$ dendritic cells, $\mathrm{F} 4 / 80^{+}$macrophages and $\mathrm{MPO}^{+}$neutrophils compared with littermate controls (Fig. 2g). Quantification of this analysis revealed a significant increased cell infiltration of all tested immune cells in the colon of Bcl-3-overexpressing mice, confirming the increased score of colitis as measured by mini-endoscopy (Supplementary Fig. 1). These data demonstrate that increased Bcl-3 expression in T cells leads to severe intestinal inflammation in mice.

Colitis in Bcl-3 ${ }^{\mathrm{TOE}}$ mice is not mediated by $\alpha \beta \mathrm{T}$ cells. To understand how T-cell-specific overexpression of Bcl-3 drives the initiation of intestinal inflammation, we analysed the effect of Bcl-3 overexpression on T-cell pathogenicity. Therefore, we used
Bcl-3-overexpressing $\mathrm{CD}^{+} \mathrm{T}$ cells to induce intestinal inflammation using the $\mathrm{T}$ cell transfer model of colitis ${ }^{31}$. However, transfer of $\mathrm{Bcl}-3^{\mathrm{TOE}} \mathrm{CD} 4^{+} \mathrm{CD} 25^{-} \mathrm{T}$ cells failed to induce colitis in $\mathrm{RAG1}^{-1-}$ recipients, whereas control $\mathrm{CD} 4{ }^{+} \mathrm{CD} 25^{-} \mathrm{T}$ cells induced colitis as measured by significantly increased clinical scores of intestinal inflammation (Fig. 3a) and weight loss (Fig. 3b). As Bcl- $3^{\mathrm{TOE}} \mathrm{CD} 4^{+} \mathrm{T}$ cells failed to mediate colitis, we assessed the proliferative capacity of these cells, as it was shown that the transfer of naive $\mathrm{T}$ cells into lymphopenic mice initiates their homeostatic proliferation ${ }^{32}$. This analysis revealed an impaired proliferative capacity of Bcl-3-overexpressing $\mathrm{CD} 4^{+} \mathrm{T}$ cells compared with control $\mathrm{CD} 4^{+} \mathrm{T}$ cells upon stimulation (Fig. 3c), an impairment that can explain the failure of these cells to induce transferred colitis. Previously, it has been demonstrated that Bcl-3 overexpression promotes T-cell survival ${ }^{33}$. To evaluate whether this holds true also in our system, we performed Annexin V and 7-aminoactinomycin D staining of purified $\mathrm{CD} 4{ }^{+} \mathrm{T}$ cells cultured for 4 days without stimulation. Indeed, we also found a survival advantage of Bcl-3-overexpressing $\mathrm{CD} 4^{+} \mathrm{T}$ cells compared with control T cells (Supplementary Fig. 2), similar to the data published by Marck et al. ${ }^{33}$. To examine whether Bcl-3 has an impact on T-cell differentiation, we analysed naive versus memory/effector 
a

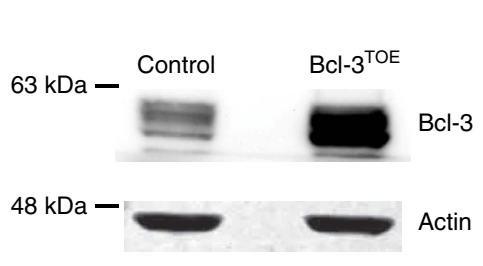

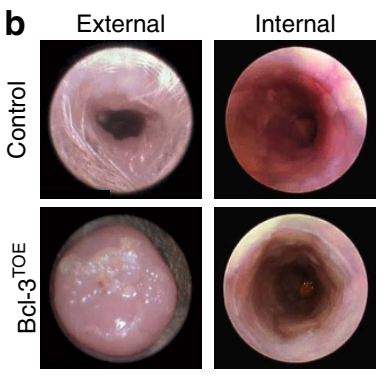

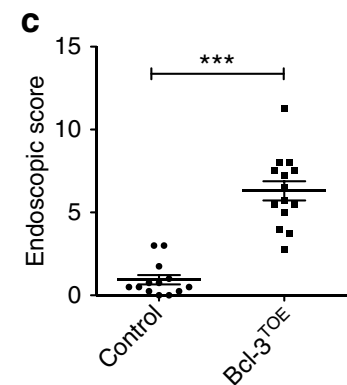

d

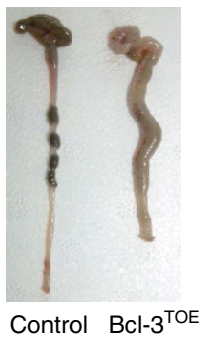

e
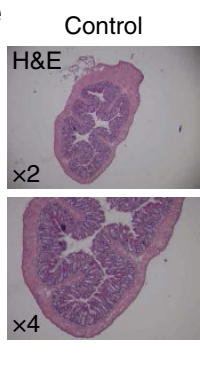
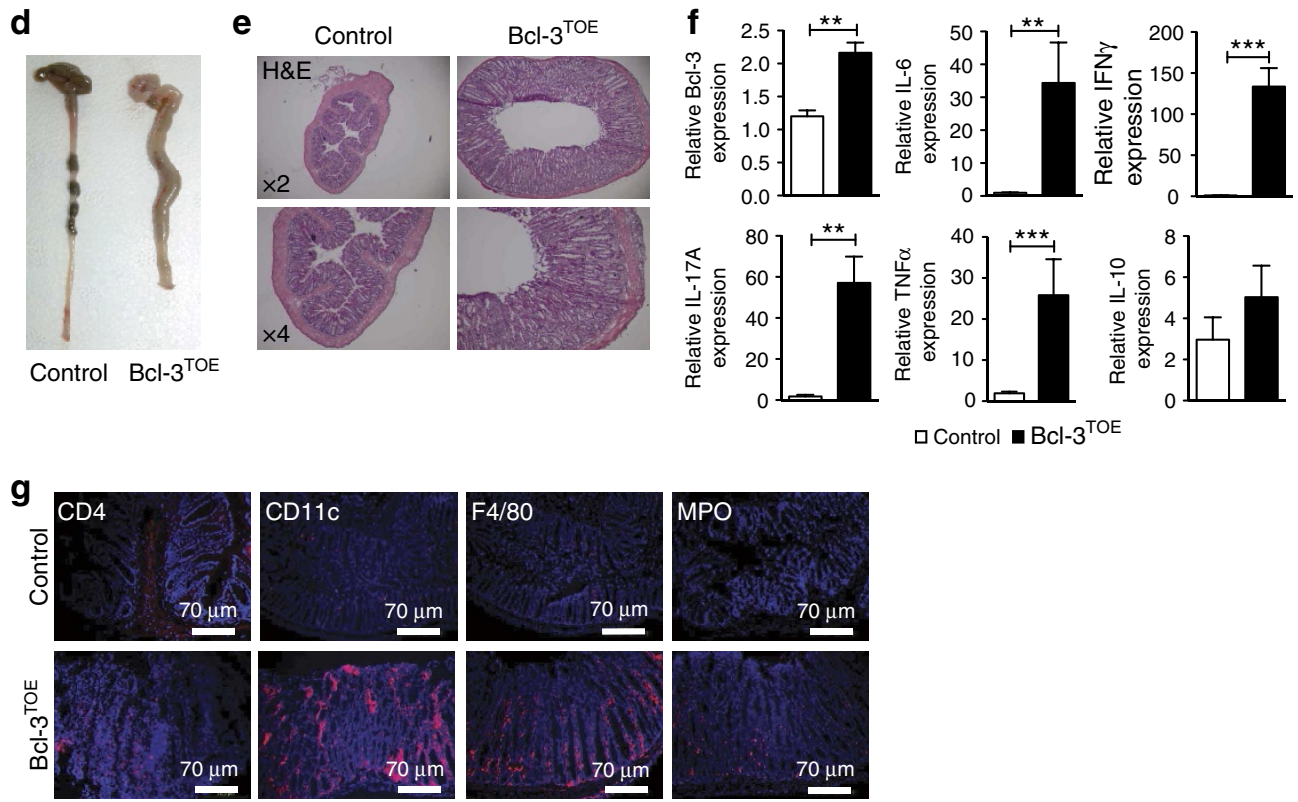

Figure 2 | Bcl-3 ${ }^{\text {TOE }}$ cells cause spontaneous colitis. (a) Western blot analysis of $\mathrm{Bcl}-3$ expression in lysates isolated from T cells of $\mathrm{Bcl}-3^{\mathrm{TOE}}$ and littermate controls using anti-Bcl-3 antibody. Actin was used as loading control. (b) Representative photographs of colons from Bcl-3 $3^{\mathrm{TOE}}$ and littermate controls at the age of 12 weeks. (c) Mini-endoscopy score of $\mathrm{Bcl}-3^{\mathrm{TOE}}(n=14)$ and littermate controls $(n=13)$ at the age of 8-18 weeks. Graph displays MEICS scores. Each symbol represents one mouse. Mean \pm s.e.m. ${ }^{\star \star \star} P<0.001$ using unpaired Student's $t$-test. (d) Representative macroscopic examination of colons from Bcl-3 $3^{\mathrm{TOE}}$ and littermate controls at the age of 12 weeks. (e) Representative haematoxylin and eosin (H\&E) staining of colons from 12 weeks old Bcl$3^{\mathrm{TOE}}$ mice $(n=4)$ and littermate controls $(n=4) . \times 2$ and $\times 4$ magnifications are shown. $(\mathbf{f})$ Quantitative RT-PCR of colonic tissues from 12 weeks old Bcl$3^{\mathrm{TOE}}$ mice $(n=5)$ and littermate controls $(n=5)$ for the indicated transcripts. Gene expression levels were normalized to HPRT. Mean \pm s.e.m. ${ }^{\star \star} P<0.01$ and ${ }^{\star \star \star} P<0.001$ using unpaired Student's $t$-test. (g) Representative immunohistochemistry of colonic cryosections from 12 weeks old Bcl-3 ${ }^{\text {TOE }}$ mice $(n=5)$ and littermate controls $(n=5)$ stained for CD4, CD11c, F4/80 and MPO (red). Nuclei were counterstained with Hoechst 3342 (blue). Scale bars, $70 \mu \mathrm{m}$. (a-g) $\mathrm{Bcl}-3^{\mathrm{OE}}$ littermate mice without $\mathrm{Cre}$ were used as controls.

$\mathrm{T}$ cells in $\mathrm{Bcl}-3^{\mathrm{TOE}}$ mice. We found a dramatic decrease in the percentage and total cell numbers of CD44 ${ }^{\text {high }}$ CD62L $\mathrm{L}^{\text {low }}$ effector/ memory $\mathrm{CD}^{+} \mathrm{T}$ cells in lymph nodes (LNs), mesenteric LN $(\mathrm{mLN})$ and spleens of Bcl-3 $3^{\mathrm{TOE}}$ mice compared with controls, whereas accordingly the percentage of naive $\mathrm{T}$ cells was significantly increased (Fig. 3d,e). This effect we already detected in young mice at the age of 4 weeks before the onset of colitis (Supplementary Fig. 3c,d). As proinflammatory cytokines IFN- $\gamma$, IL-17A and granulocyte-macrophage colony-stimulating factor have been implicated in playing important roles in the development and pathogenesis of colitis, we investigated their production by $\mathrm{CD} 4{ }^{+} \mathrm{T}$ cells from Bcl-3 $3^{\mathrm{TOE}}$ mice compared with controls. Fluorescence-activated cell sorting (FACS) analysis of $\mathrm{CD}^{+}$ $\mathrm{T}$ cells isolated from the spleen and LNs revealed a significant decrease in IL-17A and IFN- $\gamma$ expression by CD4 ${ }^{+} \mathrm{T}$ cells from $\mathrm{Bcl}-3^{\mathrm{TOE}}$ mice, whereas there was no difference in granulocytemacrophage colony-stimulating factor production when compared with $\mathrm{T} \mathrm{CD} 4{ }^{+} \mathrm{T}$ cells from littermate controls (Supplementary Fig. 4a,b). As the expression of the anti-inflammatory cytokine
IL-10 is known to have an ameliorating effect on colitis, we also investigated the production of this cytokine by $\mathrm{CD} 4{ }^{+} \mathrm{T}$ cells. Here, a significant reduction of IL-10 production by $\mathrm{Bcl}-3^{\mathrm{TOE}} \mathrm{CD} 4^{+}$ $\mathrm{T}$ cells was found, probably contributing to the observed colitis phenotype in $\mathrm{Bcl}-3^{\mathrm{TOE}}$ mice. However, the effector $\mathrm{CD} 4{ }^{+}$ $\mathrm{T}$ cells themselves do not seem to be responsible for the induction of colitis, as their numbers as well as their production of the inflammatory cytokines IFN- $\gamma$ and IL-17A are significantly reduced.

Previously, it was demonstrated that the numbers of activated $\gamma \delta \mathrm{T}$ cells are increased in the colitic area of CD and UC patients ${ }^{6,7}$. Interestingly, we detected an increased number of $\gamma \delta \mathrm{T}$ cells, in particular CD $8 \alpha^{+} \gamma \delta \mathrm{T}$ cells in the intestinal epithelial cell (intestinal epithelial lymphocyte, IEL) and LP lymphocyte (LPL) compartments of $\mathrm{Bcl}-3^{\mathrm{TOE}}$ mice as assessed by flow cytometry (Fig. 3f,g and Supplementary Fig. 5) and immunohistochemistry (Fig. 3h). Thus, $\gamma \delta \mathrm{T}$ cells seem to represent a major population involved in the intestinal inflammatory response of $\mathrm{Bcl}-3^{\mathrm{TOE}}$ mice. 
a

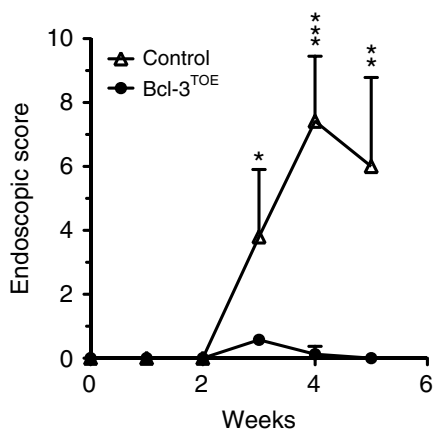

d

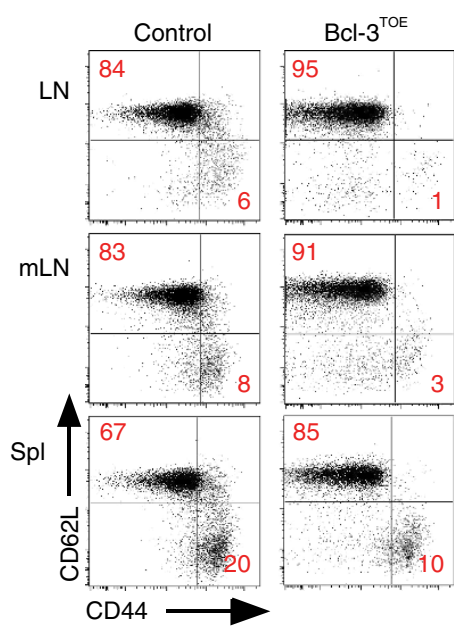

f

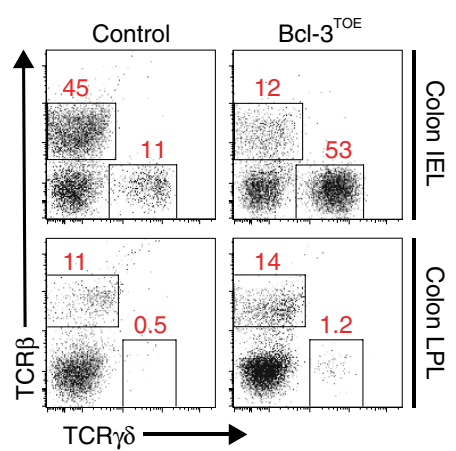

b

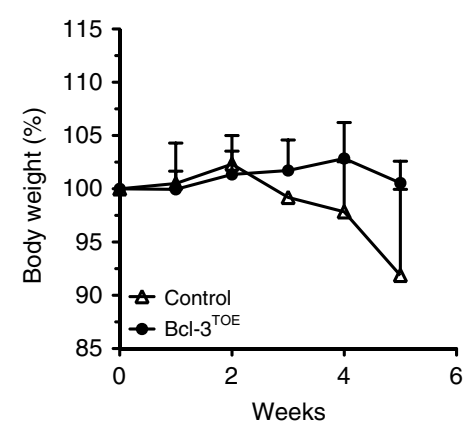

e
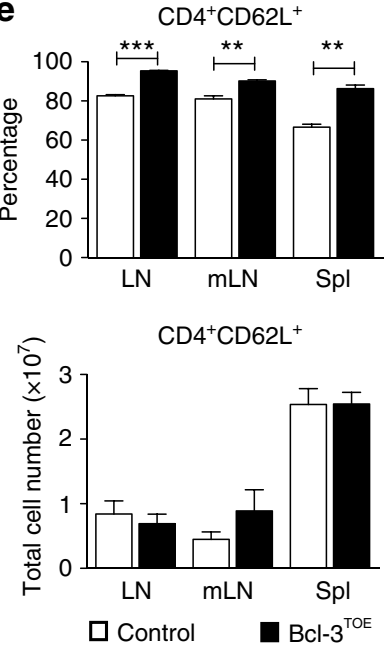

g Colon IEL

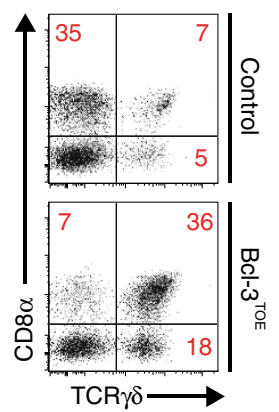

h
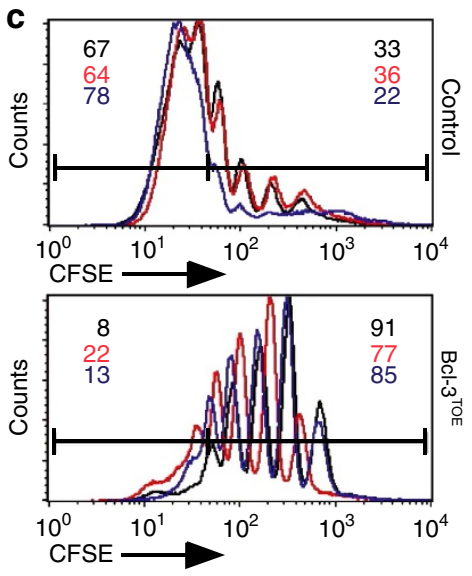

$\mathrm{CD}^{+} \mathrm{CD} 44^{+}$
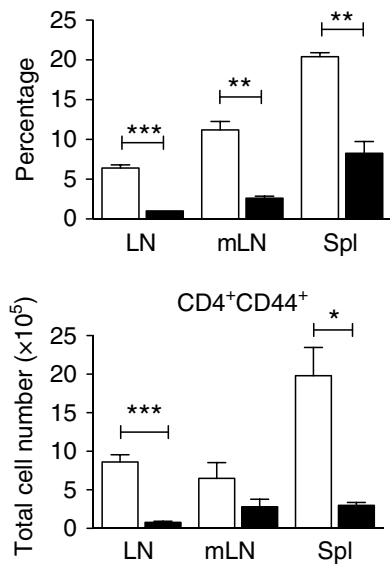
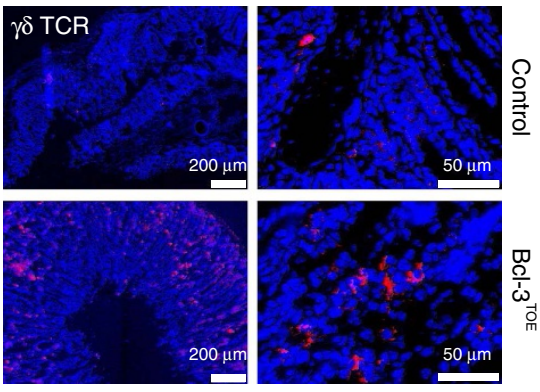

Figure 3 | Bcl-3-driven gut inflammation is dominated by $\boldsymbol{\gamma} \boldsymbol{\delta}$ T cells. $(\mathbf{a}, \mathbf{b})$ Naive CD4 ${ }^{+} \mathrm{CD} 25^{-}$T cells $\left(5 \times 10^{5}\right)$ from Bcl-3 $3^{\mathrm{TOE}}$ mice $(n=4)$ or controls $(n=3)$ were injected i.p. into RAG1 ${ }^{-/-}$recipients $(n=5$ per group). Recipients were examined for signs of colitis by mini-endoscopy shown as (a) endoscopic score and (b) body weight loss once a week for 5 weeks (mean \pm s.e.m.). ${ }^{\star \star} P<0.01$ and ${ }^{\star \star \star} P<0.001$ using unpaired Student's $t$-test. (c) In vitro proliferation assay of $\mathrm{CD} 4{ }^{+} \mathrm{CD} 25^{-}$T cells from Bcl-3 $3^{\mathrm{TOE}}$ mice $(n=3)$ and littermate controls $(n=3)$. CD4 ${ }^{+}$T cells were labelled with CFSE and cultured with anti-CD3/CD28 for 4 days. CFSE dilution was analysed by FACS. Upper histogram: CFSE dilution of control CD4 ${ }^{+}$T cells $(n=3)$ compared with $\mathrm{CD}_{4}{ }^{+} \mathrm{T}$ from Bcl-3 $3^{\mathrm{TOE}}$ mice $(n=3)$ (lower histogram). Numbers represent percentage of proliferated cells. (d) FACS analysis of LN, mLNs and splenic $(\mathrm{spl})$ cells from 8 weeks old Bcl-3TOE mice $(n=5)$ and littermate controls $(n=5)$ pre-gated on CD4 ${ }^{+}$and analysed for CD44 and CD62L expression. Numbers in quadrants represent percentage. (e) Upper panel: mean percentage and lower panel: total cell numbers of $\mathrm{CD}^{+}{ }^{+} \mathrm{CD} 62 \mathrm{~L}^{+}$and $\mathrm{CD} 4{ }^{+} \mathrm{CD} 62 \mathrm{~L}+\mathrm{T}$ cells in $\mathrm{LN}, \mathrm{mLN}$ and spl of $\mathrm{Bcl}-3^{\mathrm{TOE}}$ mice $(n=5)$ and littermate controls $(n=5)$. Shown is mean \pm s.e.m. ${ }^{\star \star} P<0.01$ and ${ }^{\star \star \star} P<0.001$ using unpaired Student's $t$-test. (f) FACS analysis of intraepithelial lymphocytes (IEL) and LPL from colon of indicated mice $(n=3)$. Cells were gated on live cells and analysed for TCR $\beta$ and TCR $\gamma \delta$ expression. Numbers represent percentage. ( $(\mathbf{g})$ FACS analysis of IEL of Bcl-3TOE mice $(n=3)$ compared with littermate controls $(n=3)$. Cells were analysed for $\operatorname{CD} 8 \alpha$ and TCR $\gamma \delta$ surface expression (percentage displayed). (h) Representative immunohistochemistry of colonic cryosections from indicated mice stained for TCR $\gamma \delta$ (red). Nuclei were counterstained with Hoechst 3342 (blue). Scale bars, $50 \mu \mathrm{m}$ (right) and $200 \mu \mathrm{m}$ (left),$n=5$. Data shown are representative for at least three independent experiments with similar results. $\mathrm{Bcl}-3^{\mathrm{OE}}$ littermate mice without Cre were used as controls. 

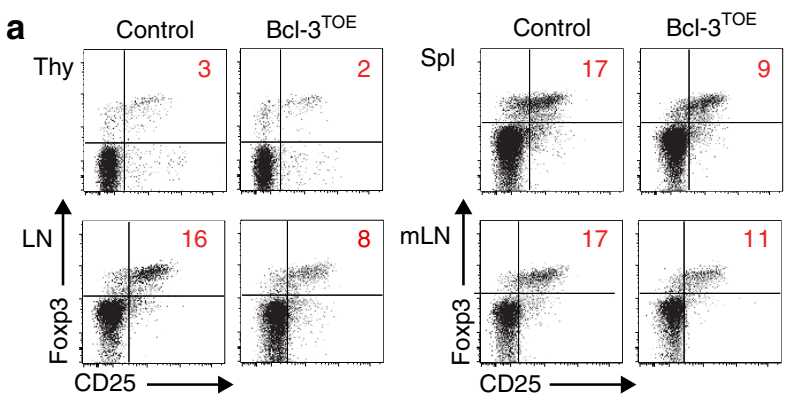

b
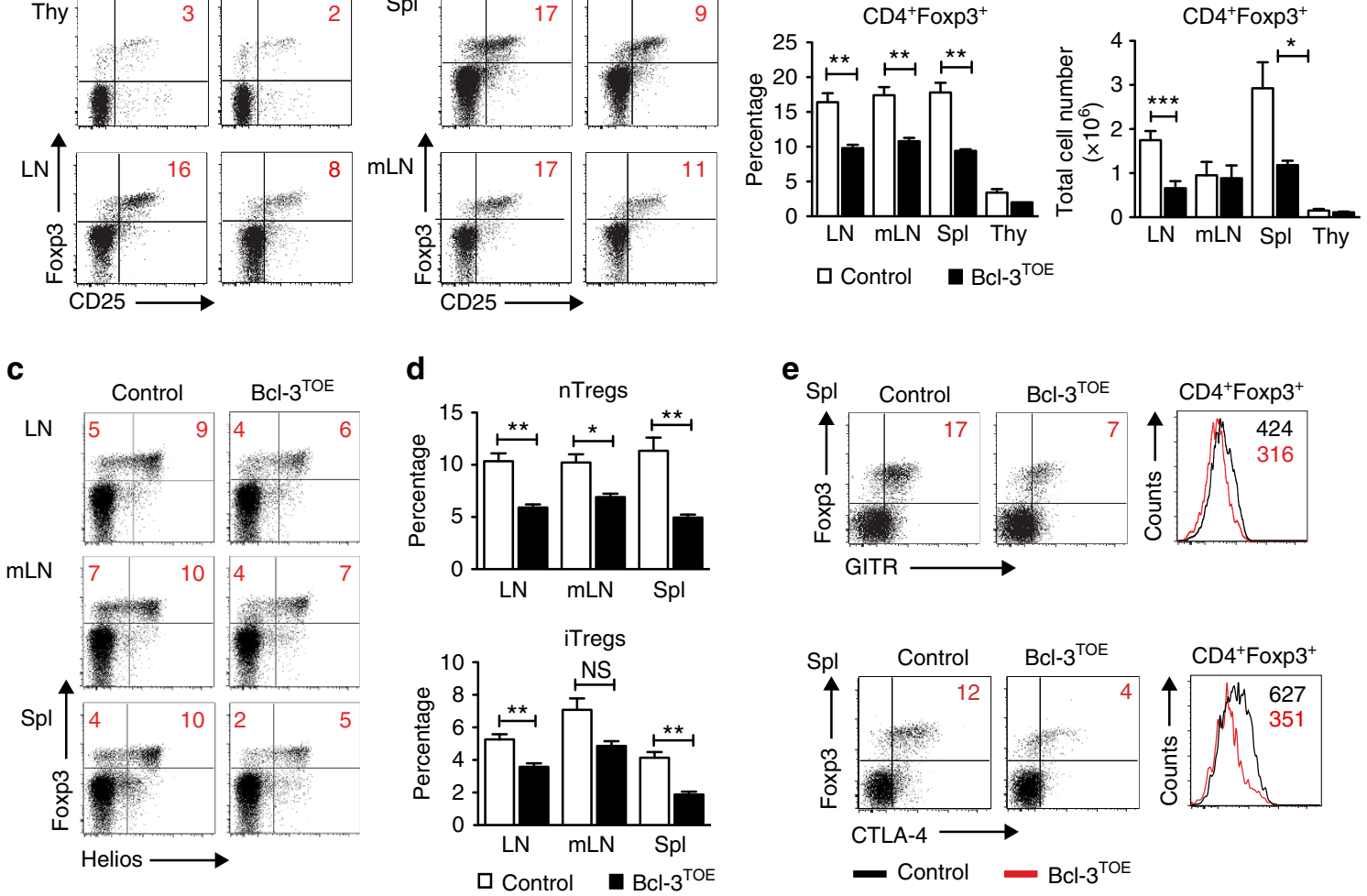

Figure 4 | Reduced numbers of Tregs in Bcl-3 ${ }^{\text {TOE }}$ mice. (a) Flow cytometric analysis of Foxp3 ${ }^{+} \mathrm{CD}_{2} 5^{+}$Treg cells from thymocytes (Thy), splenocytes $(\mathrm{Spl})$, LNs and $\mathrm{mLNs}$ of $\mathrm{Bcl}-3^{\mathrm{TOE}}(n=4)$ mice and littermate controls $(n=4)$. Numbers in quadrants represent percentage. Cells were gated on live CD4 ${ }^{+}$ T cells. Data shown are representative for at least three independent experiments with similar results. (b) Percentage (left) and absolute cell numbers (right) of $\mathrm{CD}^{+}{ }^{+}$Foxp $^{+}$T cells in $\mathrm{LN}, \mathrm{mLN}$, spleen (Spl) and thymus (Thy) from Bcl-3 ${ }^{\mathrm{TOE}}(n=4)$ mice compared with littermate controls $(n=4)$. Graphs show mean \pm s.e.m. ${ }^{\star} P<0.05,{ }^{\star \star} P<0.01$ and ${ }^{\star \star \star} P<0.001$ using unpaired Student's $t$-test. (c) Flow cytometric analysis of $\mathrm{LN}$, mLN and Spl cells gated on $\mathrm{CD}^{+}{ }^{+} \mathrm{T}$ cells for expression of Foxp3 and Helios (d), and assigned to either nTregs (Foxp3 ${ }^{+}$Helios ${ }^{+}$) or iTregs $\left(\right.$Foxp3 ${ }^{+}$Helios $^{-}$). $(\mathbf{d})$ Upper panel: percentage of nTregs of $\mathrm{Bcl}-3^{\mathrm{TOE}}$ mice $(n=4)$ compared with littermate control mice $(n=4)$. Lower panel: percentage of iTregs of Bcl-3 $3^{\mathrm{TOE}}$ mice $(n=4)$ compared with littermate control mice $(n=4)$ in $L N$, mLN and Spl. Graphs show mean \pm s.e.m. ${ }^{\star} P<0.05$, ${ }^{\star \star} P<0.01$ and ${ }^{\star \star \star} P<0.001, N S$, nonspecific using unpaired Student's t-test. (e) Flow cytometric analysis of splenocytes from Bcl-3 ${ }^{\text {TOE }}$ and littermate controls gated on $\mathrm{CD} 4^{+}$and analysed for Foxp3, GITR and CTLA-4 expression. $n=3$. Numbers in quadrants represent percentages (left). Histograms display the mean fluorescence intensity (right). Bcl-3 $\mathrm{OE}$ mice without Cre were used as littermate controls.

Bcl-3 overexpression impairs suppressive capacity of Tregs. Tregs are essential for the maintenance of immunological tolerance and immune homeostasis by suppressing the activation and expansion of potentially self-reactive $\mathrm{T}$ cells. We found a significant reduction in the percentage as well as total numbers of Foxp $3^{+}$Tregs in LNs and spleens of Bcl-3 $3^{\text {TOE }}$ mice compared with controls (Fig. 4a,b). This reduction was already present in $\mathrm{Bcl}-3^{\mathrm{TOE}}$ mice at the age of 4 weeks compared with littermate controls (Supplementary Fig. 3e,f). In mLNs of $\mathrm{Bcl}-3^{\mathrm{TOE}}$ mice, only the percentage of Foxp $3^{+}$cells was reduced, whereas the total cell number was similar to the numbers in littermate controls (Fig. 4b), probably due to the enlargement in size of $\mathrm{mLNs}$ in $\mathrm{Bcl}-3^{\mathrm{TOE}}$ mice. To explore whether the decreased number of Tregs in LN and spleen was due to reduced numbers of nTregs or iTregs, the expression of the transcription factor Helios, which was previously used as a marker for thymusderived $n$ Tregs ${ }^{34}$, was analysed. Upon Bcl-3 overexpression, the numbers of both nTregs and iTregs were significantly reduced (Fig. 4c,d). Hence, Bcl-3 appears to regulate the development and induction of nTregs, as well as iTregs. However, as a decrease in Treg numbers does not necessarily lead to immune deregulation $^{15,18,35}$, we tested whether Bcl-3 is crucial for the function and maintenance of mature Tregs. Glucocorticoidinduced tumour necrosis factor receptor (GITR) was described as a critical regulator of the interface between Tregs and immune effector cells ${ }^{36}$. FACS analysis of Treg cells from Bcl- $3^{\text {TOE }}$ mice revealed decreased number of $\mathrm{GITR}^{+}$Treg cells and, among them, reduced expression levels of GITR as measured by mean fluorescence intensities (Fig. 4e). Similarly, we found less cells expressing CTLA-4 and lower expression levels of this co-inhibitory molecule (Fig. 4e), which was shown to be a potent negative regulator of $\mathrm{T}$-cell immune responses.

To further evaluate the suppressive capacity of Bcl-3 $3^{\mathrm{TOE}}$ Tregs, we investigated the expression of the anti-inflammatory cytokine IL-10, a key cytokine mediating the inhibitory activity of Tregs, by intracellular staining. Upon stimulation, Bcl-3 ${ }^{\mathrm{TOE}}$ Tregs expressed decreased levels of IL-10 compared with Tregs from littermate controls (Fig. 5a). Similarly, quantitative RT-PCR confirmed a significant reduction in messenger RNA levels of genes relevant for Treg cell development or function, such as Ctla-4, Foxp3, Il10 and Il2r (Fig. 5b). Thus, our results suggest that Bcl-3 suppresses Treg expansion through downregulation of genes critically required for their function.

To test the function of Bcl-3 overexpressing Treg cells in vivo, we examined their ability to suppress gut inflammation. Strikingly, the transfer of $\mathrm{Bcl}-3^{\mathrm{TOE}}$ Tregs failed to prevent the development of colitis mediated by naive $\mathrm{T}$ cells, in contrast to Tregs from littermate controls (Fig. 5c). To further confirm that the 
a

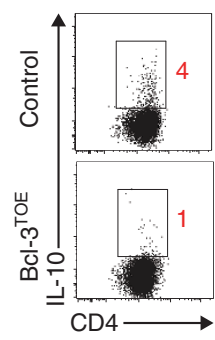

d

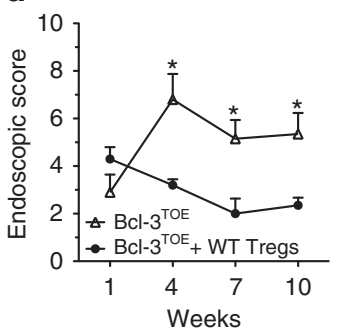

b

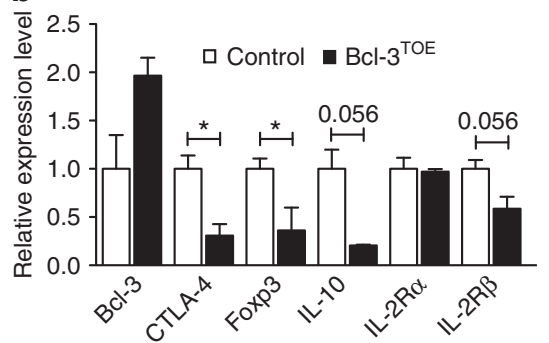

e

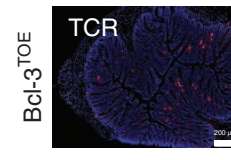

CD4
C

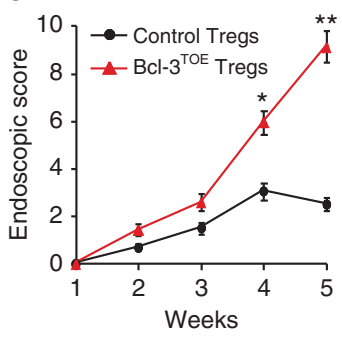

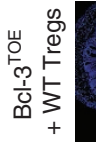
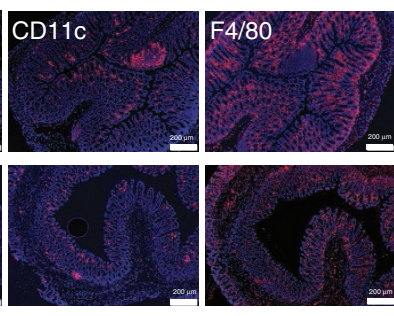

Figure 5 | Bcl-3 ${ }^{\text {TOE }}$ Tregs display diminished suppressive capacity. (a) Flow cytometric analysis of MACS-purified CD4 ${ }^{+}$CD25 ${ }^{+}$Treg cells of the indicated genotypes restimulated with PMA/lonomycin and BrefeldinA for $4 \mathrm{~h}$. Cells are gated on Foxp3 ${ }^{+}$and analysed for IL-10 expression. $n=3$. (b) Quantitative RT-PCR of MACS purified CD4 ${ }^{+} \mathrm{CD} 25^{+}$Treg cells from the indicated mice $(n=3)$. Shown are transcription counts of the indicated genes normalized to HPRT and littermate controls. ${ }^{\star} P<0.05$ using unpaired Student's $t$-test. $(\mathbf{c}) \mathrm{CD} 4{ }^{+} \mathrm{CD} 25^{-}$T cells $\left(5 \times 10^{5}\right)$ isolated from control mice $(n=3)$ by MACS were adoptively transferred into RAG1 ${ }^{-/}$mice alone or together with $5 \times 10^{5} \mathrm{CD} 4^{+} \mathrm{CD} 25^{+} \mathrm{T}$ cells isolated from control or $\mathrm{BCl}-3^{\mathrm{TOE}}$ mice $(n=5)$. RAG1 ${ }^{-/}-$recipients were examined for signs of colitis by mini-endoscopy at the indicated time points. MEICS scores are shown. Mean \pm SEM. $n=5$ RAG $1^{-/}$- recipient mice per group. ${ }^{\star} P<0.05$ and ${ }^{\star \star} P<0.01$ using unpaired Student's $t$-test. (d) $C D 4{ }^{+}$CD $25^{+}$Treg cells $\left(1 \times 10^{5}\right)$ isolated from littermate controls $(n=3)$ by MACS were adoptively transferred into 6 weeks old Bcl-3 ${ }^{\text {TOE }}$ mice $(n=5)$ every 3 weeks. As controls Bcl-3 $3^{\text {TOE }}$ mice were injected with PBS $(n=5)$. Bcl-3 $3^{\text {TOE }}$ recipients receiving either Tregs or PBS were examined for signs of colitis by mini-endoscopy at the indicated time points. MEICS scores are shown. Mean \pm s.e.m. ${ }^{\star} P<0.05$ using unpaired Student's $t$-test. (e) Representative immunohistochemistry of colonic cryosections of the indicated genotypes stained for TCR $\gamma \delta, C D 4, C D 11 c$ and F4/80 (red). Nuclei were counterstained with Hoechst 3342 (blue). Scale bars, $200 \mu \mathrm{m} . n=5$ mice per group. $\mathrm{Bcl}-3^{\mathrm{OE}}$ mice without $\mathrm{Cre}$ were used as littermate controls.

spontaneous intestinal inflammation observed in the Bcl- $3^{\mathrm{TOE}}$ mice was due to a defect in the Treg suppressive capacity, we tested whether control Tregs transferred into $\mathrm{Bcl}-3^{\mathrm{TOE}}$ mice can prevent this inflammation. Indeed, transfer of control Tregs ameliorated the development of colonic inflammation in $\mathrm{Bcl}-3^{\mathrm{TOE}}$ mice, as these mice displayed remission of disease compared with the untreated $\mathrm{Bcl}-3^{\mathrm{TOE}}$ control group (Fig. 5d). In line with these data, the number of infiltrating immune cells such as $\gamma \delta \mathrm{T}$ cells, $\mathrm{CD} 4{ }^{+} \mathrm{T}$ cells, CD11c ${ }^{+}$dendritic cells and $\mathrm{F} 4 / 80^{+}$ macrophages was reduced in $\mathrm{Bcl}-3^{\mathrm{TOE}}$ mice upon transfer of control Tregs (Fig. 5e). Hence, these data demonstrate that high expression levels of Bcl-3 inhibit the suppressive function of Tregs, leading to intestinal inflammation in $\mathrm{Bcl}-3^{\mathrm{TOE}}$ mice.

Bcl-3 regulates Treg development and function. To determine whether Bcl-3 influences Treg cell development and function by extrinsic factors or via an intrinsic mechanism, we crossed $\mathrm{Bcl}-3^{\mathrm{OE}}$ mice with the Foxp3-IRES Cre mouse strain ${ }^{37}$ to obtain mice, which overexpress Bcl-3 specifically in Tregs but not conventional $\alpha \beta \mathrm{T}$ cells. Strikingly, the analysis of the Treg compartment in mLNs revealed an increased percentage of Tregs in Bcl-3 $3^{\text {TregOE }}$ mice compared with littermate controls, whereas the Treg numbers in $\mathrm{Bcl}-3^{\mathrm{TOE}}$ mice was significantly reduced (Fig. 6a,b). As in Bcl-3 $3^{\mathrm{TOE}}$ and $\mathrm{Bcl}-3^{\text {TregOE }}$ mice the GFP expression is coupled to $\mathrm{Bcl}-3$ expression, we are able to distinguish $\mathrm{Bcl}-3$-overexpressing Tregs from $\mathrm{GFP}^{-}$Tregs expressing wild-type (wt) levels of Bcl-3 in the same mouse. Of note, in Bcl-3 $3^{\mathrm{TOE}}$ mice $14 \%$ of Foxp $3^{+}$Tregs were negative for GFP expression, pointing to the existence of Tregs that escaped CD4-Cre-mediated recombination (Fig. 6c). In $\mathrm{Bcl}-3^{\text {TregOE }}$ mice, this effect was much more pronounced, with about $50 \%$ of Foxp $3^{+} \mathrm{GFP}^{-} \mathrm{T}$ cells. Interestingly, the analysis of CTLA-4 expression in $\mathrm{GFP}^{+}$and $\mathrm{GFP}^{-}$Tregs of $\mathrm{Bcl}-3^{\mathrm{TOE}}$ and $\mathrm{Bcl}-3^{\text {TregOE }}$ mice revealed a significant reduction of CTLA-4 expression and geometric mean fluorescence intensity in the $\mathrm{GFP}^{+}$Treg compartment when compared with $\mathrm{GFP}^{-}$Tregs (Fig. 6d). Taken together, these data indicate that Bcl-3 negatively regulates the development and function of Tregs intrinsically.

Bcl-3 interacts with NF-кB member p50 in Treg cells. As changes in NF- $\kappa \mathrm{B}$ member expression levels might be the cause of impaired Treg function, we analysed whether Bcl-3 overexpression leads to altered expression levels or localizations of some NF- $\kappa \mathrm{B}$ family members. As the expression levels and the nuclear localizations of p50, p52 and p65 were similar to those of controls (Fig. 7a), we hypothesized that increased Bcl-3 expression directly modulates the activity of NF- $\kappa \mathrm{B}$ in Tregs.

Bcl-3 was shown to inhibit or activate NF- $\kappa \mathrm{B}$-mediated gene expression in the nucleus through direct binding to p50 and/or p52 homodimers, which has been demonstrated in several cell lines and primary $B$ and $T$ cells ${ }^{19,20,38-40}$. However, whether Bcl-3 also binds p50 specifically in Tregs has not been addressed so far. We therefore performed immunoprecipitation experiments with extracts from wt Tregs using antibodies against Bcl-3. These experiments show that endogenous Bcl-3 binds directly to p50 also in Tregs (Fig. 7b). To visualize their localization, we performed confocal microscopy in Tregs using antibodies 

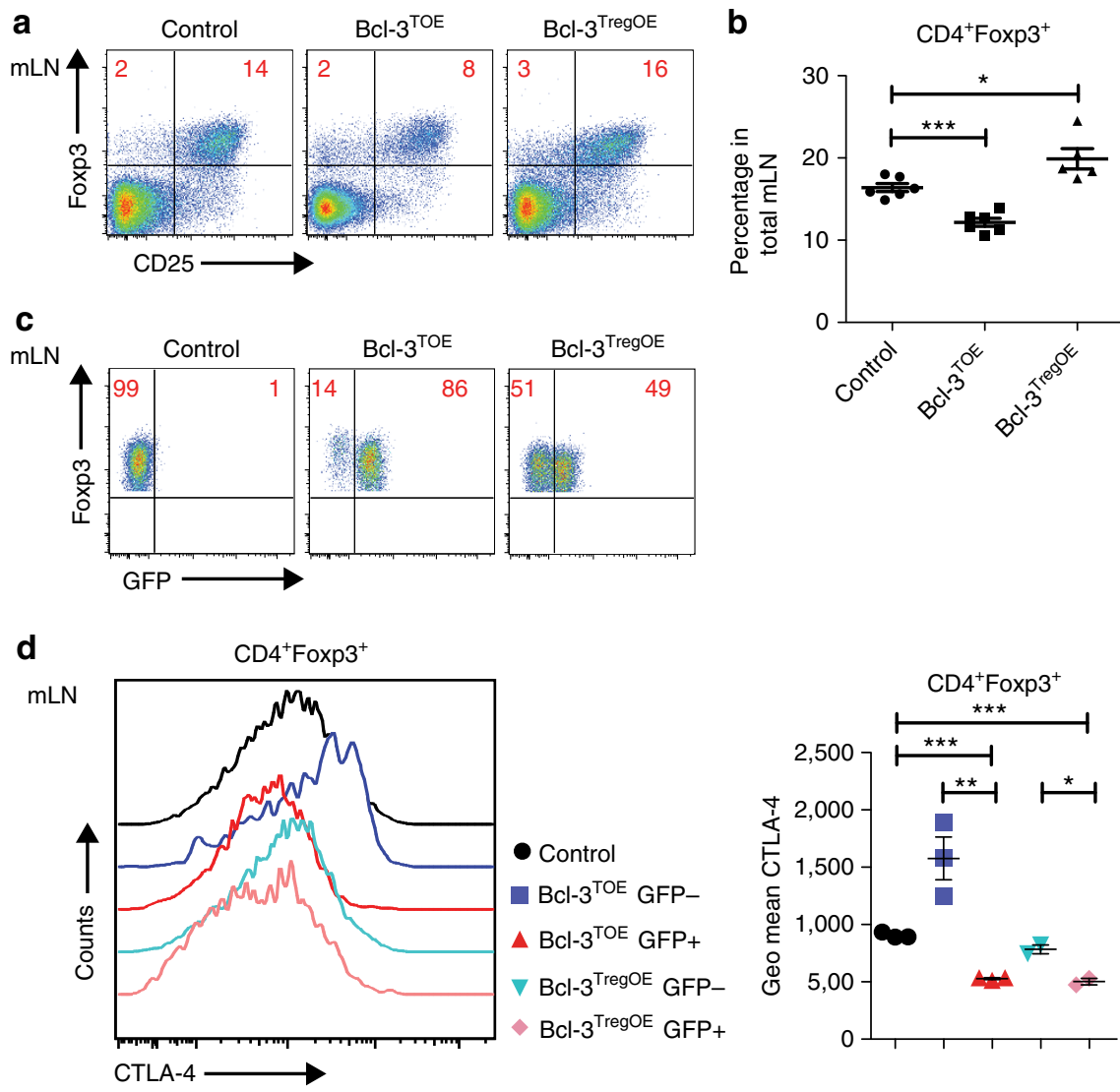

Figure 6 | Bcl-3 inhibits Treg development intrinsically. (a) Flow cytometric analysis of $\mathrm{mLNs}$ from Bcl-3 $3^{\mathrm{TOE}}, \mathrm{Bcl}-3^{\text {TregOE }}$ and littermate control mice using indicated antibodies. Numbers in plots/quadrants indicate percentage. Cells are gated on live CD4 ${ }^{+} \mathrm{T}$ cells. Data shown are representative of at least three independent experiments with $n=3$. (b) Percentage of $\mathrm{CD}^{+}{ }^{+}$Foxp3 ${ }^{+}$T cells in total $\mathrm{mLN}$ from Bcl-3 $3^{\mathrm{TOE}}, \mathrm{Bcl}-3^{\text {TregOE }}$ and littermate control mice. Graphs show mean \pm s.e.m. ${ }^{\star} P<0.05$ and ${ }^{\star \star \star} P<0.001$ using unpaired Student's $t$-test. $n=5-6$ mice per group. (c) Cells from $\mathrm{mLN}$ of Bcl-3 ${ }^{T O E}, \mathrm{Bcl}-3^{T r e g O E}$ and littermate control mice were analysed for Foxp3 and GFP expression by flow cytometry. Numbers in plots/quadrants indicate percentage of $\mathrm{CD}^{+}{ }^{+} \mathrm{Foxp}^{+} \mathrm{GFP}^{-}$and $\mathrm{CD} 4{ }^{+} \mathrm{Foxp}^{+} \mathrm{GFP}^{+}$cells. Cells are gated on live $\mathrm{CD}^{+}{ }^{+}$Foxp3 ${ }^{+} \mathrm{T}$ cells. Data shown are representative of at least three independent experiments with $n=3$ (d) Flow cytometric analysis of $\mathrm{mLN}$ from Bcl-3 $3^{\mathrm{TOE}}, \mathrm{Bcl}-3^{\text {TregOE }}$ and littermate control mice gated either on $\mathrm{CD}^{+}{ }^{+}$Foxp3 ${ }^{+} \mathrm{GFP}^{+}$or $\mathrm{CD}^{+}{ }^{+}$Foxp3 ${ }^{+} \mathrm{GFP}+$ cells. Histogramm (left) displays CTLA-4 expression and graph (right) shows the Geometric Mean Fluoreszence Intensity of CTLA-4 expression for the indicated groups with $n=3$ mice per group. $\mathrm{Bcl}-3^{\mathrm{OE}}$ mice without Cre were used as littermate controls.

directed against endogenous Bcl-3 and transfected p50. Indeed, both proteins localize in close proximity in the nucleus of Treg cells (Supplementary Fig. 6a).

As Bcl-3 overexpression led to reduced expression of Foxp3, as well as IL-10, CTLA-4 and IL-2R (Fig. 4g), we performed electrophoretic mobility shift assays (EMSA) with DNA probes from intergenic regions within these genes. These probes highlight active $\mathrm{H} 3 \mathrm{~K} 4$ trimethylation in Tregs ${ }^{41}$ and contain a recognizable $\kappa \mathrm{B}$ enhancer-binding site ${ }^{42}$. Incubating these probes with nuclear lysates from cells overexpressing p50 revealed binding of p50 specifically to $\kappa \mathrm{B}$ sites, as complexes were nearly absent with DNA probes with point mutations in $\kappa \mathrm{B}$-binding sites (Supplementary Fig. $6 \mathrm{~b}$ ). We now wondered whether Bcl-3 could alter p50 binding to sequences from these regions as it has been previously suggested from different contexts ${ }^{39,43,44}$. Therefore, we performed pull-down assays using Treg lysates and Bcl-3-expressing lysates with baits is appropriate from the $I L-2 R \alpha$, Foxp3 and $I L-10$ gene segments, as well as chromatin immuneprecipitations (CHiP) for $\mathrm{p} 50$ in Tregs from Bcl-3 $3^{\mathrm{TOE}}$ mice.

Pull-down assays revealed that binding of endogenous p50 to DNA was inhibited in the presence of Bcl-3 protein to an extent similar to reactions using a NF- $\kappa \mathrm{B}$ mutant probe (Fig. $7 \mathrm{c}$ ). Although p50 binding was not completely abolished, the weakened binding seems to reflect the specific binding of p50 to DNA, as competition assays with cold probes revealed similar results (Supplementary Fig. 6c).

Most importantly, this effect of Bcl-3 inhibiting p50 binding to DNA occurs in Tregs themselves on Treg-relevant genes as seen by $\mathrm{CHiP}$ experiments with $\mathrm{p} 50$-specific antibodies. We could observe inhibited binding of p50 to the endogenous Foxp3, as well as CTLA-4 promoter in Tregs of Bcl-3 $3^{\mathrm{TOE}}$ mice, compared with Treg cells of littermate controls (Fig. 7d). Although we observe in all assays only a $\sim 50 \%$ reduction in binding of p50 to DNA by elevated levels of Bcl-3, this inhibition was consistently observed through all experiments and reflects also the extent to which NF- $\mathrm{BB}$ targeted genes were reduced in expression (Fig. 5b). Together, these experiments demonstrate that Bcl-3 can inhibit the binding of p50 to promoters and sequences containing a NF- $\kappa \mathrm{B}$ site and are important for Treg development and function.

Bcl-3 inhibits p50-mediated NF-кB gene activity. To test whether Bcl-3 overexpression had a direct effect on p50-mediated gene regulation in Tregs, we designed a reporter vector containing the Foxp3 promoter with a $\mathrm{\kappa B}$-binding site that has been previously shown to bind p50 (ref. 45). Indeed, these 
a

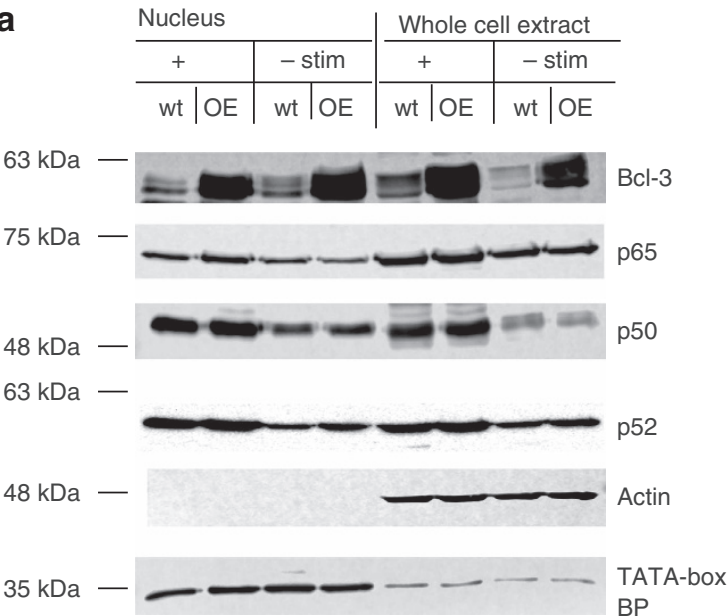

C

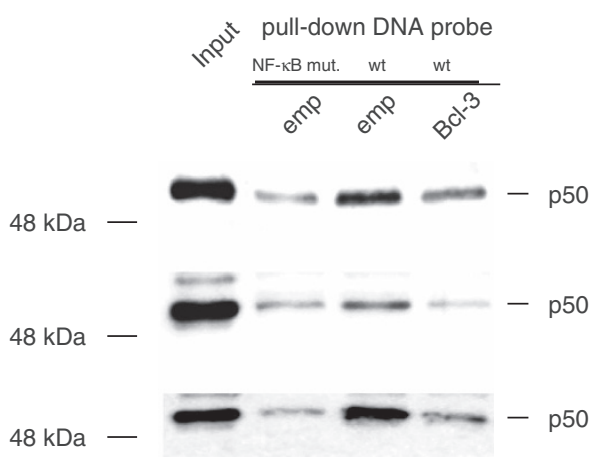

b
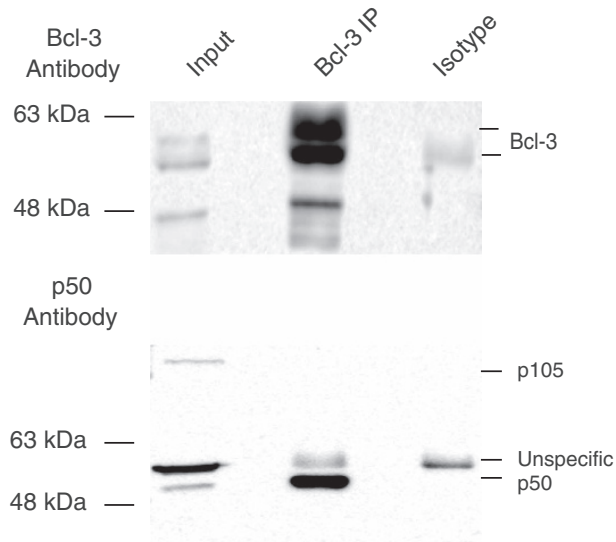

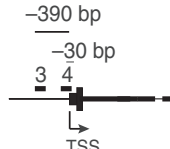

CTLA-4

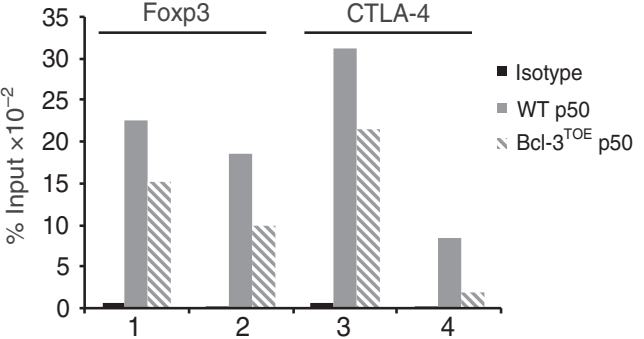

Figure 7 | Bcl-3 prevents p50 binding to the Foxp3 and CTLA-4 promoter. (a) Western blot analysis of Bcl-3 and the NF- $\mathrm{kB}$ family members p50, p52 and $\mathrm{p} 65$ in nuclear versus whole extract of $\mathrm{Bcl}-3^{\mathrm{TOE}}$ and littermate controls using Tregs either unstimulated (left) or restimulated for $2 \mathrm{~h}$ with PMA/Ionomycin (right). One representative blot from two independent experiments is shown. (b) Immunoprecipitation with Bcl-3 antibodies using protein extracts from in vitro differentiated Tregs, restimulated with PMA/lonomycin for $4 \mathrm{~h}$ and followed by immunoblot analysis with antibodies against Bcl-3 or p50. One representative blot from two independent experiments is shown. (c) Pull-down experiments with DNA probes from promoters of IL2Ra, Foxp3 CN2 (from top to bottowm) with protein extracts from Tregs to which $\mathrm{Bcl}-3$ or empty vector overexpressing lysates were added. One out of two experiments is demonstrated. (d) CHiP assay using p50 and isotope control antibodies antibodies were performed in in vitro differentiated Tregs from $\mathrm{BCl}{ }^{\mathrm{TOE}}$ mice and littermate controls. Primer were designed as indicated for two sites within the CTLA-4 and Foxp3 Promoter region. One of two representative biological examples is shown.

reporter assays revealed diminished activity of the Foxp3 promoter in Tregs from Bcl-3 $3^{\mathrm{TOE}}$ compared with Tregs isolated from littermate controls (Fig. 8a). To test whether this inhibitory effect of Bcl-3 overexpression on gene activity was due to its direct interaction and regulation of p50, we used a Bcl-3 mutant that is unable to interact with p50 (ref. 46) (Fig. 8b). Strikingly, this mutant was not able to repress gene activity compared with wt Bcl-3 construct. In the presence of this construct, we observed enhanced promoter activity (Fig. 8c), possibly functioning as a dominant-negative protein. As NF- $\mathrm{KB}$ family members are described to act as heterodimers for activation and as homodimers for repression of genes ${ }^{19-22}$, we tested whether Bcl-3 affects gene expression through its interaction with the p50/p65 heterodimer. Indeed, we found that endogenous p65 from Tregs is inhibited in its binding to designed IL- $2 \mathrm{R} \alpha$ and Foxp 3 probes in the presence of lysates from Bcl-3-expressing cells. This inhibition in binding was abrogated when we used the $\mathrm{Bcl}-3$ mutant that is unable to interact with p50 (Supplementary Fig. 7a). Most importantly, when performing CHiP experiments for p65 in Bcl- $3^{\text {TOE }}$ Tregs, we observed inhibited binding to the Foxp3 and CTLA-4 promoter in Treg cells from Bcl- $3^{\mathrm{TOE}}$ mice compared with Tregs from littermate controls (Supplementary Fig. 7b), although the inhibition is weaker compared with that seen for $\mathrm{p} 50$ (comparing Fig. 7d and Supplementary Fig. 7b). This finding highlights that, through its interaction with p50, Bcl-3 inhibits the binding of p50/p65 heterodimers to DNA. This result explains the reduced gene activation of $\mathrm{NF}-\kappa \mathrm{B}$-targeted genes in Tregs that we observe in the presence of higher levels of Bcl-3.

We could demonstrate that the suppression of Treg functionality is a result of $\mathrm{Bcl}-3$ interacting with p50 and preventing its binding to DNA in Tregs. This Bcl-3-p50 interaction seems to affect p50/p65 heterodimer binding to DNA potentially explaining the negative effect of $\mathrm{Bcl}-3$ on NF- $\kappa \mathrm{B}$-mediated transcription of Treg genes. Hence, our data demonstrate the importance of fine-tuning $\mathrm{NF}-\mathrm{\kappa B}$ activity during immune responses to prevent the development of autoimmune inflammation.

\section{Discussion}

IBD is characterized by the infiltration of $\mathrm{T}$ cells that cause colon damage and attract innate inflammatory immune cells. We found drastically elevated expression levels of Bcl-3 in CD4 ${ }^{+} \mathrm{T}$ cells isolated from patients with $\mathrm{CD}$ and $\mathrm{UC}$, underlining a role for $\mathrm{Bcl}-3$ in the pathogenesis of IBD. In mice, we could define a clear 
a

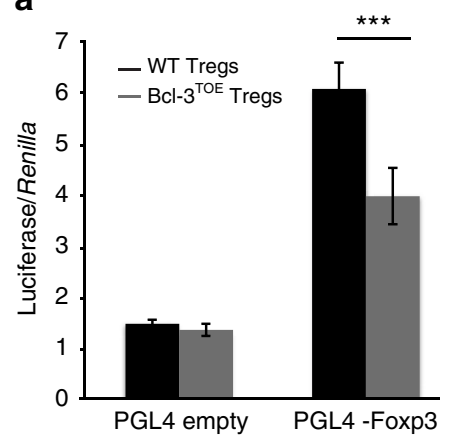

b

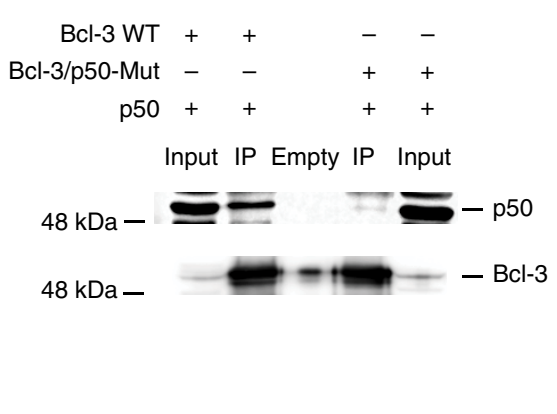

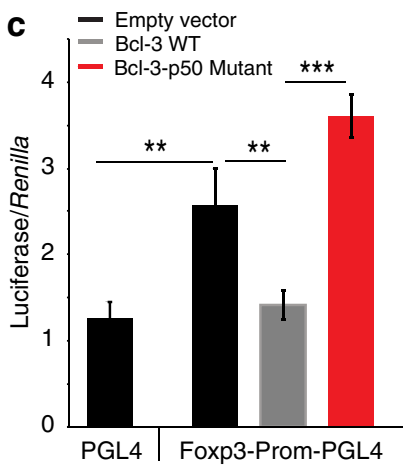

Figure 8 | Bcl-3 inhibits Foxp3 promoter activity via direct binding to p50. (a) Reporter assays with constructs containing the endogenous Foxp3 promoter, using in vitro differentiated Tregs restimulated with PMA/lonomycin from Bcl-3 ${ }^{\mathrm{TOE}}$ mice. The Luciferase reads from the pGL4 plasmid that contained the Foxp3 promoter or empty were normalized to a Renilla transfection control plasmid. One representative out of two independent experiments with four parallel transfections is shown. Mean \pm s.e.m. ${ }^{\star \star \star} P<0.001$ using unpaired Student's $t$-test. (b) Immunoprecipitations using nuclear extracts from HEK293T cells transfected with Bcl-3 wt and Bcl-3 mutant co-transfected with p50 were performed, followed by immune blot analysis using Bcl-3 and p50 antibodies. (c) Reporter assays for Foxp3 gene activity as described in a with in vitro expanded T cells transfected with Bcl-3 wt and Bcl-3-p50 mutant constructs. Normalization was performed as in a. One representative out of two independent experiments with four parallel transfections is shown. Mean \pm s.e.m. ${ }^{\star \star} P<0.01$ and ${ }^{\star \star \star} P<0.001$ using unpaired Student's $t$-test; $s>3$.

role for Bcl-3 in intestinal inflammation, as mice overexpressing Bcl-3 in T cells develop spontaneous colitis. This disease was accompanied by infiltration of various pro-inflammatory cells into the colon, including $\gamma \delta \mathrm{T}$ cells, which might account for the increased levels of IL-17A detected in the colon of these mice.

Previous studies using Bcl-3 deficient animals suggested an intrinsic function of $\mathrm{Bcl}-3$ in constraining the plasticity of pathogenic $\mathrm{T}_{\mathrm{H}} 1$ cells ${ }^{27}$. Interestingly, we found that high expression of $\mathrm{Bcl}-3$ in $\mathrm{CD}^{+}$cells leads to a reduced number of pathogenic effector T cells. Indeed, the spontaneous colitis seen in our model is not driven by conventional $\alpha \beta \mathrm{T}$ cells, as these cells fail to proliferate and differentiate into pathogenic $\mathrm{T}$ cells and in accordance fail to induce colitis in a passive T-cell transfer model.

We found a suppressive dysfunction of Tregs from Bcl- $3^{\text {TOE }}$ mice, as these cells secrete decreased levels of IL-10, shown to be crucial for suppressing $\gamma \delta$ T-cell expansion and for the prevention of spontaneous colitis in vivo ${ }^{4}$. Whether or not the reduced IL-10 production by $\mathrm{Bcl}-3$-overexpressing Tregs is the sole reason for the colitis is not clear, as we also noticed decreased expression levels of Foxp3, CTLA-4, GITR and IL-2R in these Treg cells. In accordance to the above data, the transfer of wt Tregs into $\mathrm{Bcl}-3^{\mathrm{TOE}}$ mice blocked the development of colitis and inhibited $\gamma \delta$ T-cell expansion in the colonic compartment of these mice. These findings underline the suppressive dysfunction of Tregs overexpressing Bcl-3.

Surprisingly, mice overexpressing Bcl-3 specifically in Treg cells (Bcl-3 $3^{\text {FoxP3OE }}$ mice) did not develop any signs of colitis probably due to the very high percentage of GFP ${ }^{-}$Foxp3 ${ }^{+}$Treg cells, which was less pronounced using CD4-Cre. These GFP ${ }^{-}$ Foxp $^{+}$cells could have escaped Cre-mediated recombination and fill up the Treg compartment through a proliferative and/or survival advantage over the cells that overexpress Bcl-3. However, also the different time points of Cre activity and the cells targeted could be a potential explanation of this inconsistency. Using the CD4-Cre mouse, Bcl-3 is overexpressed in CD4-expressing T cells during T-cell development, which results in elevated Bcl-3 levels already before Treg development. In addition, in these mice all conventional $\mathrm{T}$ cells overexpress $\mathrm{Bcl}-3$ possibly indirectly also influencing Treg cell development/proliferation and/or viability of these cells. In contrast, enforced expression of Bcl-3 using Foxp3-Cre mice occurs later, starting only after Treg cells already developed and only in Foxp $3^{+}$Treg leaving all conventional $\mathrm{T}$ cells unaffected, and therefore functionally normal. This difference in time of overexpression and the targeted cells may affect how Treg cells are capable to deal with Bcl-3 overexpression.

It is well established that Bcl-3 plays an important role in $\mathrm{NF}-\kappa \mathrm{B}$ regulation, either promoting or inhibiting target gene expression depending on the cell type and stimulus received ${ }^{47}$. Bcl-3 selectively interacts with p50 and p52 subunits of NF- $\kappa B$ via its ankyrin domains, thereby regulating NF- $\kappa \mathrm{B}$-dependent gene transcription ${ }^{20,48-50}$. In addition to its numerous posttranslational modifications influencing its mode of action, Bcl-3 was also shown to act as an adaptor molecule, possibly building a platform for other coactivators or repressors to p50/p50 homodimers, thereby possibly influencing its mode of action $^{51}$. Previously, it has been suggested that NF- $\kappa B$ activity is important for Treg development and differentiation, as mice lacking p65, p50 and c-Rel show diminished Treg cell development and defective Foxp3 gene expression ${ }^{15-17}$. However, p50 and c-Rel-deficient mice do not develop spontaneous autoimmunity even though these mice display decreased numbers of Tregs and defective peripheral Treg differentiation. Therefore, the exact mechanistic role of $\mathrm{NF}-\kappa \mathrm{B}$ signalling in controlling immune homeostasis remains unknown.

Aberrant expression of $\mathrm{Bcl}-3$ results in a wide range of defects within the immune system but so far, no clear correlation between $\mathrm{Bcl}-3$ expression and subsequent NF- $\kappa \mathrm{B}$ activation has been reported for Treg function. In contrast, for T-helper subsets a clear role for $\mathrm{Bcl}-3$ in regulating NF- $\kappa \mathrm{B}$ activity has been demonstrated. Here, it was shown that Bcl-3 controls T-helper cell plasticity by preventing the binding of c-Rel and p65 to NF- $\mathrm{KB}$ binding sites in the ROR $\gamma \mathrm{t}$ promoter ${ }^{27}$. In the absence of Bcl-3, c-Rel and p65 induce Rorc expression leading to Th17 differentiation $^{52}$. In Th1 cells, Bcl-3 mediates the stabilization of inhibitory p50 homodimers on NF- $\kappa \mathrm{B}$-binding sites, thereby restricting $\mathrm{ROR} \gamma \mathrm{t}$ expression ${ }^{27}$. Of note, our data using $\mathrm{Bcl}-3$ transgenic mice clearly demonstrate that Bcl-3 overexpression has a global effect on T-helper cell differentiation and impairs Treg function. We found that enforced Bcl-3 expression has a cell type-specific suppressive function in Treg cells leading to repression of NF- $\kappa \mathrm{B}$ target gene expression, whereas inflammation and/or NF- $\kappa \mathrm{B}$-driven Bcl-3 expression, as seen 
the gut of those mice, results in elevated NF- $\mathrm{KB}$ target gene expression. This is in line with previously suggested contextdependent functions of Bcl-3 (ref. 47). We show that in Tregs Bcl-3 directly interacts with $\mathrm{p} 50$, thereby preventing its binding to DNA and thus directly inhibiting NF- $\mathrm{KB}$ target gene expression, thereby fine-tuning the function of Tregs. How this is achieved is not clear, as Bcl-3 cannot bind to DNA, but it does exert its functions in the nucleus. We show that $\mathrm{Bcl}-3$ is also localized in the nucleus of Treg cells. One possible mechanism is the described interaction of Bcl-3 with histone deacetylases leading to transcriptional termination ${ }^{53,54}$. We also observe transcriptional inhibition in Treg cells by enforced Bcl-3 expression on p50-regulated genes. In addition, we also show weaker binding of p50 to DNA in the presence of high levels of Bcl-3. However, the exact molecular mechanism for this still remains unclear.

We further propose that the direct interaction of Bcl-3-p50 also prevents the binding of p50/p65 heterodimers to DNA but not through a direct mechanism. p65 was recently illustrated to be essential for Treg stability and controlling the functionality of Tregs, as p65 inactivation specifically in Tregs induces multi-focal autoimmune disease in mice ${ }^{17}$. Therefore, inhibition of $\mathrm{p} 50 / \mathrm{p} 65$ activation by $\mathrm{Bcl}-3 / \mathrm{p} 50$ complexes is likely to be responsible for the suppressive dysfunction of Bcl-3-overexpressing Tregs, leading to chronic inflammatory colitis in $\mathrm{Bcl}-3^{\mathrm{TOE}}$ mice.

Here we define a cell-type-specific molecular mechanism by which Bcl-3 regulates NF- $\mathrm{KB}$-dependent gene expression in Treg cells. Our analyses demonstrate the importance to fine-tune Bcl-3 expression for the development and function of Treg cells, as elevated levels of Bcl-3 expression leads to dysfunctional Tregs resulting from diminished NF- $\kappa \mathrm{B}$ activity. Specifically targeting the activity of Bcl-3 in IBD may represent an effective strategy for the inhibition of gut inflammation.

\section{Methods}

Patients biopsy collection. For the analysis of Bcl-3 expression in humans, colonic tissue samples were obtained from patients with IBD (CD and UC) and control patients without IBD, who underwent colonic resection or routine colonoscopy (Table 1). Colonic specimens from biopsies and surgical resections from patients with IBD were studied and compared with control samples. The collection of human samples was approved by the Ethics committee of the University Hospital, Friedrich-Alexander-Universität Erlangen-Nürnberg. Human samples derived from the University Medical Center of the Johannes Gutenberg were analysed from therapeutically indicated biopsies following informed consent and was approved by the Ethical Committee of the Landesärztekammer Rheinland-Pfalz.

Immunohistochemistry in IBD patients and control subjects. Immunofluorescence of cryo- or paraffin sections from gut specimens of control subjects and patients with IBD was performed using the TSA Flurescein systems (PerkinElmer) and a fluorescence microscope (Olympus IX81) ${ }^{55}$. In brief, sections were fixed in $4 \%$ paraformaldehyde in PBS, before staining paraffin was removed, followed by incubation with avidin-biotin-blocking reagent (Vector, SP-2001) and Roti-Immunoblock (ROTH, T144.1, 1:10 dilution in TBST $+2 \%$ BSA) for suppression of nonspecific background staining. Then sections were stained at $4{ }^{\circ} \mathrm{C}$ overnight in a humidified chamber with primary antibody (anti-human CD4, OKT4, BioLegend, 1:50 dilution) or (anti-Bcl-3, sc-185, Santa Cruz, 1:100 dilution). Slides were incubated at room temperature for $30 \mathrm{~min}$ with biotinylated secondary antibody (111-065-144, Jackson ImmunoResearch, 1:1,000 dilution) or (anti-mouse, BA-9200, Vector, 1:1,000 dilution) followed by incubation with TSA kit reagents. Nuclei were counterstained with Hoechst 33342 (Molecular Probes, Invitrogen, 1:10,000 dilution in TBS). Histological sections that were not optimal for a proper analysis were discarded from the analysis.

Isolation of human LP T cells. LP mononuclear cells were isolated from freshly obtained specimens from control and UC patients using Lamina Propria Dissociation Kit (Miltenyi Biotech, catalogue number: 130-097-410). In brief, tissue was incubated in Hank's balanced salt solution with EDTA and dithiothreitol (DTT). After mechanical dissection by vortexing and passing through a cell strainer, cell suspension of epithelial cells and IEL was removed. After incubation with collagenase, DNase and dispase for $30 \mathrm{~min}$ at $37^{\circ} \mathrm{C}$, the suspension was subjected to further purification of T cells. LP T cells were prepared from the

\section{Table 1 | Patient's characteristic.}

\begin{tabular}{|c|c|c|c|}
\hline$n$ (control) & 7 & & \\
\hline n (Crohńs disease) & 5 & & \\
\hline n (ulcerative colitis) & 11 & & \\
\hline Age (years) & $22-64$ & & \\
\hline Female & $56.5 \%$ & & \\
\hline Group & Gender & Age & Localization \\
\hline Control & $\hat{0}$ & 64 & Sigmoid colon \\
\hline Control & q & 30 & Sigmoid colon \\
\hline Control & o & 26 & Descending colon \\
\hline Control & $\hat{0}$ & 33 & Sigmoid colon \\
\hline Control & o & 28 & Transverse colon \\
\hline Control & $\hat{0}$ & 41 & Term. ileum \\
\hline Control & $\hat{0}$ & 60 & Descending colon \\
\hline$C D$ & q & 31 & Anastomose \\
\hline$C D$ & o & 35 & Term. ileum \\
\hline$C D$ & $\hat{\sigma}$ & 28 & Sigmoid colon \\
\hline$C D$ & $\hat{\sigma}$ & 29 & Caecum \\
\hline$C D$ & q & 30 & Term. ileum \\
\hline UC & $\hat{\sigma}$ & 36 & Sigmoid colon \\
\hline UC & 암 & 39 & Sigmoid colon \\
\hline UC & $\hat{0}$ & 56 & Sigmoid colon \\
\hline UC & q & 51 & Sigmoid colon \\
\hline UC & q & 46 & Sigmoid colon \\
\hline UC & q & 23 & Sigmoid colon \\
\hline UC & 우 & 46 & Rectum \\
\hline UC & q & 23 & Sigmoid colon \\
\hline UC & q & 33 & Descending colon \\
\hline UC & $\widehat{0}$ & 39 & Sigmoid colon \\
\hline UC & $\hat{0}$ & 51 & Sigmoid colon \\
\hline
\end{tabular}

resultant cell population as described previously ${ }^{56}$. T cells were analysed for Bcl-3 expression by western blot analysis.

Mice. $\mathrm{Bcl}-3^{\mathrm{OE}}$ mice were generated as described previously ${ }^{30}$. $\mathrm{Bcl}-3^{\mathrm{OE}}$ mice were crossed to CD4-Cre mice ${ }^{57}$ to generate Bcl-3 $3^{\mathrm{TOE}}$ mice and to Foxp3-IRES-Cre mice ${ }^{37}$ to generate $\mathrm{Bcl}-3^{\text {TregOE }}$ mice. Age- and gender-matched genetically modified animals carrying loxP sites without Cre transgene ( $\mathrm{Bcl}-3{ }^{\mathrm{OE}}$ mice) were used as control mice on C57BL/6 background. Animals requiring veterinary attention were provided with appropriate care and excluded from experiments. All experiments were performed with 4- to 18-week-old mice (unless otherwise specified). RAG1 ${ }^{-I-}, \mathrm{Bcl}-3^{\mathrm{OE}}, \mathrm{Bcl}-3^{\mathrm{TOE}}$ and $\mathrm{Bcl}-3^{\mathrm{TregOE}}$ mice were bred in the animal facility at the University of Mainz. All animal experiments were in accordance with the guidelines of the Translational Animal Research Center, University of Mainz, or to the guidelines of the Helmholtz Zentrum München.

Real-time PCR analysis. Total RNA was isolated using RNeasy Kit (catalogue number: 74104, Qiagen) according to the manufacturer's instruction. Quantitative real-time PCR was performed using Quantitec Primer Assay (Qiagen). Catalogue number: IL-6: QT00098875; IFN- $\gamma$ : QT01038821; IL-17A: QT00103278; TNF $\alpha$ : QT00104006; IL-10: QT00106169.

Flow cytometry. Single-cell suspensions were prepared from different organs. Red blood cells in cell suspensions from the spleen were lysed with tris-ammonium chloride pH 7.2. Cells were incubated with combinations of antibodies to cell surface determinants. CD4, CD8 $\alpha$, CD25, CD44, CD62L, CTLA-4, Foxp3, GITR, Helios, IL-10, TCR $\beta$ and TCR $\gamma \delta$ antibodies were purchased either from BD, eBioscience or Biolegend (see Supplementary Table 10). All samples were acquired on a FACS Canto II BD and results were analysed with FlowJo software. Absolute numbers of thymocyte, LN and splenocyte subpopulations were calculated based on their percentage and total number.

Staining of Foxp3 together with retention of GFP. Single-cell suspensions were prepared from mLNs. Cells were stained and fixed as described previously ${ }^{58}$. In brief, cells were surface stained with antibodies purchased from eBioscience, BD and BioLegend (see Supplementary Table 10). Cells were fixed with $2 \%$ formaldehyde to retain EGFP. For intracellular staining of Foxp3 with EGFP retention, $1 \times$ Perm buffer (eBioscience) was used. Samples were acquired on a FACS Canto II BD and results were analysed with FlowJo software. 
Cell purification. Cells from spleen and LNs were purified using CD4 ${ }^{+}$ MicroBeads (Miltenyi Biotech, catalogue number: 130-049-201), the CD4 ${ }^{+}$ $\mathrm{CD}^{2} \mathrm{~L}^{+}$T-cell isolation kit (Miltenyi Biotech, catalogue number: 130-093-227) or the $\mathrm{CD} 4{ }^{+} \mathrm{CD} 25^{+}$Treg cell isolation kit (Miltenyi Biotech, catalogue number: 130-091-041) according to the manufacturer's instruction. Purity as determined by flow cytometry was over $95 \%$.

Isolation of IEL and LPL. IELs and LPLs were isolated as described previously ${ }^{59}$. In brief, large intestine IEL and LPL were isolated by using a combination of mechanical dissociation and enzymatic digestion. The isolated cells were used directly for FACS analysis.

Survival assay. $\mathrm{CD} 4{ }^{+} \mathrm{T}$ cells were isolated by using MicroBeads (Miltenyi Biotech, catalogue number: 130-049-201) from spleens and LNs of 5-week-old $\mathrm{Bcl}-3^{\mathrm{TOE}}$ mice and control littermates. Triplicates of $1 \times 10^{5} \mathrm{CD} 4^{+} \mathrm{T}$ cells were cultured for 4 days in T-cell media at $37^{\circ} \mathrm{C}$. Each day cells were counted, stained for AnnexinV (Immunotools, catalogue number: 31490016) and 7-aminoactinomycin D (BD Pharmingen, catalogue number: 559925) according to the manufacturer's instruction and analysed by FACS.

\section{Western blot analysis of NF-KB members using Bcl-3 ${ }^{\text {TOE }}$ Tregs.}

In vitro-generated Tregs were restimulated with phorbol 12-myristate 13-acetate (PMA) and ionomycin for $2 \mathrm{~h}$ and nuclear extracts were prepared. The antibodies used were as follows: anti-Bcl-3: Santa-Cruz (sc-185, 1:1,000 dilution) and Abgent (WA-AP9337c, 1:1,000 dilution), anti-p50: Santa-Cruz, (E-10, 1:1,000 dilution) and Abcam (ab7971, 1:1,000 dilution), anti-p65: Abcam (ab7970, 1:1,000 dilution), anti-p52: Cell Signaling (4882, 1:1,000 dilution), anti-TATA binding protein TBP[EPR3826(2)]: Abcam (ab125009, 1:2,000 dilution) and anti-Actin: Millipore (MAB1501R, 1:5,000 dilution)

Adoptive transfer model of colitis. Magnetic-activated cell sorting (MACS)purified naive $\mathrm{CD} 4{ }^{+} \mathrm{CD} 62 \mathrm{~L}^{+} \mathrm{T}$ cells $\left(5 \times 10^{5}\right)$ from wt and $\mathrm{Bcl}-3^{\mathrm{TOE}}$ mice were injected intraperitoneallty (i.p.) in 6- to 8-week-old RAG1 ${ }^{-/}$- mice. After the cell transfer, RAG1 ${ }^{-1-}$ recipients were weight weekly and monitored by miniendoscopy.

In vivo Treg suppression assay. MACS-purified naive $\mathrm{CD} 4{ }^{+} \mathrm{CD} 25^{-} \mathrm{T}$ cells $\left(5 \times 10^{5}\right)$ from wt mice were injected i.p. into 6- to 8-week-old RAG1 ${ }^{-1-}$ mice alone or with equal numbers of wt or Bcl-3 $3^{\mathrm{TOE}}$ MACS-purified $\mathrm{CD} 4^{+} \mathrm{CD} 25^{+}$ Tregs. After the cell transfer, RAG1 ${ }^{-1-}$ recipients were weight weekly and monitored by mini-endoscopy.

Adoptive transfer of Tregs. Tregs $\left(\mathrm{CD} 4{ }^{+} \mathrm{CD} 25^{+}\right)$were isolated from $\mathrm{LN}$ and spleen of littermate control mice by MACS purification and injected intravenously $\left(1 \times 10^{5}\right)$ into $\mathrm{Bcl}-3^{\mathrm{TOE}}$ mice, three times every 3 weeks. Mice were monitored by mini-endoscopy every 3 weeks. After 3 weeks from the last injection of wt Tregs, colon tissue samples were collected for histological analysis.

In vivo high-resolution mini-endoscopy analysis of the colon. For monitoring of colitis activity, a high-resolution video endoscopic system (Karl Storz) was used. To determine colitis activity, mice were anaesthetized by injecting a mixture of ketamine (Ketavest $100 \mathrm{mg} \mathrm{ml}^{-1}$, Pfizer) and xylazine (Rompun 2\%, Bayer Healthcare) i.p. and monitored by mini-endoscopy at indicated time points. Endoscopic scoring of five parameters (translucency, granularity, fibrin, vascularity and stool) was performed.

Histology and immunohistochemistry in mice. Colonic cryosections were stained with haematoxylin and eosin. For immunohistochemistry, colon samples were isolated from control and colitic mice at indicated time points. Immunofluorescence of cryosections was performed using the TSA Cy3 System (NEL704A001KT, PerkinElmer) and a fluorescence microscope (IX70; Olympus) using primary antibodies against CD4 (catalogue number: 553043, BD Pharmingen, rm4-5, 1:00 dilution), CD11c (catalogue number 550283, BD, dilution 1:200), MPO (ab15484 Abcam, 1: 20 dilution), F4/80 (BM8 eBioscience, lot 14-4801-81, 1: 1,000 dilution) and TCR $\gamma \delta$ (BD Bioscience, clon No: h57-597 catalogue number: 553169 , dilution 1:100). In brief, cryosections were fixed in 4\% PFA for $20 \mathrm{~min}$ followed by sequential incubation with methanol, avidin/biotin (Vector Laboratories) and protein blocking reagent (catalogue number: T144.1 Roti-ImmunoBlock, Roth) to eliminate unspecific background staining. Slides were then incubated overnight with primary antibody specific for the respective antigen. Subsequently, the slides were incubated for $30 \mathrm{~min}$ at room temperature with biotinylated secondary antibodies (Jackson Immunoresearch catalogue number: 127-065-160 and BD Pharmingen catalogue number: 554014). All samples were finally treated with streptavidin-horseradish peroxidase and stained with Tyramide (Cy3) according to the manufacturer's instructions (catalogue number:

NEL704A001KT, PerkinElmer). Before examination, nuclei were counterstained with mounting medium for fluorescence with 4,6-diamidino-2-phenylindole (catalogue number: H-1200, Vector).

Confocal microscopy in $\mathbf{T}$ cells. Treg cells from $\mathrm{Bcl}-3^{\mathrm{TOE}}$ mice were differentiated, expanded and electroporated with Flag-tagged p50 constructs as in the section: Luciferase reporter Assays. Cells were re-stimulated with PMA and Ionomycin for $2 \mathrm{~h}$ and attached to cover glass slides with poly-L-lysine (SIGMA, P4832). Bcl-3 was stained with anti-Bcl-3 antibodies (Santa Cruz, sc-185 C-14) and p50 was visualized by staining for Flag tag with anti-Flag antibody (E. Kremmer, 6F7).

T-cell isolation and in vitro differentiation. Naive $\mathrm{CD} 4{ }^{+} \mathrm{CD} 62 \mathrm{~L}{ }^{+} \mathrm{T}$ cells were isolated by using MicroBeads (Miltenyi Biotech, catalogue number: 130-104-453) or Dyna and Detacha Beads (Invitrogen, catalogue number: 11445D and catalogue number: $12406 \mathrm{D}$, respectively) from spleens of 8- to 12 -week-old C57BL/6 mice or of Bcl-3 ${ }^{\mathrm{TOE}}$ and control littermates, and activated with plate-bound anti-CD3 (using first anti-hamster, Novartis, catalogue number: 55397 then anti-CD3 in solution: clone: $2 \mathrm{C} 11 \mathrm{H}: 0.1 \mu \mathrm{g} \mathrm{ml}^{-1}$ ) and soluble anti-CD28 (clone: $37 \mathrm{~N}$ : $\left.1 \mu \mathrm{g} \mathrm{ml}^{-1}\right) \cdot \mathrm{T}_{\mathrm{H}} 0$ and Treg cultures were additionally supplemented with blocking antibodies anti-IL-4 (clone: $11 \mathrm{~B} 11,10 \mu \mathrm{g} \mathrm{ml}{ }^{-1}$ ) and anti-IFN- $\gamma$ (clone: Xmg-121, $10 \mu \mathrm{g} \mathrm{ml}^{-1}$ ). All antibodies were obtained in collaboration with and from Elisabeth Kremmer (Helmholtz Center Munich). For Treg differentiation additionally the following cytokines were added: rmIL- 2 and rmTGF- $\beta$ (both: R\&D Systems, $5 \mathrm{ng} \mathrm{ml}^{-1}$ ). For expansion of Treg cells, cells were cultured in RPMI and 2,000 units Proleukin S (MP Biomedicals, catalogue number: 02238131). For experiments, only samples were used that achieved between 55-85\% Foxp3 positive cells (Staining Kit, BD Bioscience: catalogue number: 00552300).

Immunoprecipitation in $\mathbf{T}$ cells. $\mathrm{T}_{\mathrm{H}} 0$ and Treg cells were generated and expanded as described above and $1 \times 10^{8}$ cells were lysed in $4 \mathrm{ml}$ Meister Lysis Buffer $(20 \mathrm{mM}$ Tris/ $\mathrm{HCl} \mathrm{pH} \mathrm{7.5,} \mathrm{0.25 \%} \mathrm{NP40,} 150 \mathrm{mM} \mathrm{NaCl}, 1,5 \mathrm{mM} \mathrm{MgCl}_{2}$ and Protease Inhibitors (Roche, catalogue number: 04693132001) und $1 \mathrm{mM} \mathrm{DTT).} 60 \mu \mathrm{l}$ Protein-G beads (Dynabeads Protein G, catalogue number: 10004D) were pre-coupled with $10 \mu \mathrm{g}$ antibodies (anti-Bcl-3: Santa-Cruz, catalogue number: sc-185; anti-p50: Abcam, catalogue number: ab7971) in PBS and 0.05\% Tween and then equilibrated in Meister Lysis Buffer and added to lysed cells and incubated for $4 \mathrm{~h}$. Washing was performed with Lysis Buffer. Proteins were eluted with $80 \mu 11 \times$ SDS Lämmli loading dye, one-fourth was used for western blot analysis. Blottings were incubated with anti-p50 (Santa-Cruz, catalogue number: sc-8414) and anti-Bcl-3 antibodies (Santa-Cruz, catalogue number: sc-185).

Luciferase assay in T cells. Reporter assays were performed as previously described $^{60}$. The Foxp3 promoter $(-422-+20$, position at Exon1) was cloned into the pGL4.10 Luciferase reporter plasmid (Promega, catalogue number: E6651) The TK-Renilla reporter plasmid (Promega, catalogue number: E2241) was used as a control. Treg cells, polarized for $42 \mathrm{~h}$ as described above and expanded for 1 day were transfected with different Luciferase reporter and control Renilla reporter constructs by using the Mouse T Cell Nucleofector Kit (LONZA, catalogue number: V4XP-3032) according to the manufacturer's instructions. Sixteen hours after electroporation, $\mathrm{T}$ cells were re-stimulated for $6 \mathrm{~h}$ with PMA $\left(25 \mathrm{ng} \mathrm{ml}^{-1}\right.$, Santa Cruz) and Ionomycin $\left(1 \mu \mathrm{g} \mathrm{ml}{ }^{-1}\right.$, Santa Cruz) and then harvested and measured with the Dual Luciferase reporter system (Promega, catalogue number: E1910). Renilla activity was used to normalize transfection efficiency and Luciferase activity.

Electrophoretic mobility shift assays. HEK293T cells (obtained by ATCC, CRL-11269) were transfected by calcium phosphate transfection with p50-expressing plasmids. Nuclear lysates were generated two days after transfection by incubation in $2 \mathrm{ml}$ (per $10 \mathrm{~cm}$ plate) Hypotonic Buffer $(10 \mathrm{mM}$ Hepes pH 7.6, $10 \mathrm{mM} \mathrm{KCl}, 0.1 \mathrm{mM}$ EGTA, $1.5 \mathrm{mM} \mathrm{MgCl}, 1 \mathrm{mM}$ DTT, $0.5 \mathrm{mM}$ phenylmethylsulfonyl fluoride and the complete protease inhibitor mixture (Roche, catalogue number: 11697498001) and then lysed with the addition of $0.01 \%$ Triton X-100. After centrifugation at maximum speed in an Eppendorf microfuge for $15 \mathrm{~s}$ the nuclear pellet was resuspended in $250 \mu \mathrm{l}$ of the Nuclear Buffer (420 mM NaCl, $20 \mathrm{mM}$ Hepes pH 7.9, 0.2 mM EDTA, 25\% Glycerol, $1 \mathrm{mM}$ DTT, $0.5 \mathrm{mM}$ phenylmethylsulfonyl fluoride with complete protease inhibitor mixture). Nuclear proteins were extracted with intermittent vortexing and incubation for $15 \mathrm{~min}$ at $4^{\circ} \mathrm{C}$. In vitro binding assays were performed using reagents from the light-shift chemiluminescent EMSA kit (Thermo Scientific, catalogue numbre: 20148) according to the manufacturer's protocol, with the exception of using IR Dye800-labelled probes (Table 2). Protein-DNA complexes were separated by using 6\% TBE Gels (Invitrogen) and LiCor Model 2800 used to visualize EMSA bands.

Pull-down with DNA probes in T cells. For one pull-down reaction, $1 \times 10^{6} \mathrm{~T}$ cells polarized and expanded as described above and nuclear extracts were generated as described in the section 'Electrophoretic mobility shift assays', using 


\section{Table 2 | DNA sequences used in EMSAs and pulldowns.}

IL-10 promoter:

CTTTGCCAGGAAGGCCCCACTGAGCCTTCA

IL-10 promoter mutant:

CTTTGCCAAAAAGGCCAAACTGAGCCTTCA

CTLA-4 H3 intron-2:

GTTGACACGGGACTGTACCTCTGCAAGG

CTLA-4 H3 intron-2 mutant:

GTTGACACGAAACTGTAAATCTGCAAGG

Foxp3 CNS2:

ACCCTACCTGGGCCTATCCGGCTACAG

Foxp3 CNS2 mutant:

ACCCTACCTAAGCCTATAAGGCTACAG

IL-2 RA promoter:

GCAAGGGTTTGGAAAGGCCCCTTGTGGGTG

IL-2 RA promoter mutant:

GCAAGGGTTTAAAAAGGCAACTTGTGGGTG

Sequences were chosen by conservation peaks and a potential NF- B binding side and GG and CC within the motive were mutated.

$1 \mathrm{ml}$ Hypotonic Buffer and $90 \mu \mathrm{l}$ Nuclear Buffer for $1 \times 10^{6} \mathrm{~T}$ cells. Binding reactions of nuclear extracts to DNA probes were performed as in EMSA reactions (using the Thermo Scientific buffers) scaled up 20 times for one pull-down reaction, using $90 \mu \mathrm{l}$ nuclear extracts of T cells plus $12 \mu \mathrm{l}$ Bcl-3-overexpressing $293 \mathrm{~T}$ lysates or empty $293 \mathrm{~T}$ lysates. DNA probes were the same sequences as used in EMSAs, biotin-labelled. Binding reactions were incubated for in total $1 \mathrm{~h}$, then $40 \mu \mathrm{l}$ Streptavidin beads were added (Invitrogen, catalogue number: 65001) and rotated overnight at $4{ }^{\circ} \mathrm{C}$. Proteins were eluted the next day with $2 \times$ SDS Lämmli Buffer and visualized via western blotting with anti-p50 antibodies (Abcam ab7971). DNA sequences used in EMSAs and pulldowns are described in Table 2.

CHiP experiments in Treg cells. Bcl-3-overexpressing Tregs and Tregs from littermate controls were generated as described before. Tregs $\left(20 \times 10^{6}\right)$ were cross-linked with $1 \%$ Formaldehyde (10 min, room temperature) and crosslinking reaction was stopped by the addition of glycine to a final concentration of $0.125 \mathrm{M}$. $\mathrm{CHiP}$ assays were performed as described (PU1. DeKoter, Harinder Singh) with the following minor changes: after sonification for 40 cycles (Bioruptor; $30 \mathrm{~s}$ on, $30 \mathrm{~s}$ off at high), chromatin was diluted to $500 \mu \mathrm{l}$ total volume in nuclei-lysis buffer with protease inhibitors and added to $1.5 \mathrm{ml}$ CHiP IP buffer (0.01\% SDS, $1.1 \%$ Triton X-100, $1.2 \mathrm{mM}$ EDTA, $16.7 \mathrm{mM}$ Tris- $\mathrm{HCl} \mathrm{pH} 8.1$ and $16.7 \mathrm{mM} \mathrm{NaCl})$ with pro-

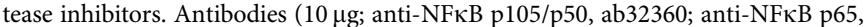
ab16502) were coupled to $50 \mu \mathrm{l}$ Dynabeads Protein G (10004D) for $1 \mathrm{~h}$ at room temperature and further blocked with sonicated salmon sperm DNA for $30 \mathrm{~min}$ before washing. Beads and diluted chromatin were incubated at $4{ }^{\circ} \mathrm{C}$ over night and washed with $1 \mathrm{ml}$ of the following buffers each at RT for $5 \mathrm{~min}$ with rotation: buffer I (0.1\% SDS, $1 \%$ Triton X-100, 2 mM EDTA, $20 \mathrm{mM}$ Tris-HCl pH 8.1 and $150 \mathrm{mM}$ $\mathrm{NaCl})$, Buffer II (0.1\% SDS, $1 \%$ Triton X-100, 2 mM EDTA, $20 \mathrm{mM}$ Tris-HCl pH 8.1 and $500 \mathrm{mM} \mathrm{NaCl})$, Buffer III $(0.25 \mathrm{M} \mathrm{LiCl}, 1 \% \mathrm{NP}-40,1 \mathrm{mM}$ EDTA and $10 \mathrm{mM}$ Tris- $\mathrm{HCl} \mathrm{pH} \mathrm{8.1),} 2 \times \mathrm{TE} \mathrm{pH}$ 8.0. DNA precipitation was performed as described $^{61}$. All quantitative RT-PCRs were performed by the SYBR green method with the following Primers: CTLA4 1 forw. $5^{\prime}$-CTTCTACTTGGCAGGCTGGG- $3^{\prime}$ and rev. $5^{\prime}$-CCACTGCCCTCCTTGGTATC- $3^{\prime}$. CTLA4 2 forw. $5^{\prime}$-CCACACTG ATAGCTGGCCTT- $3^{\prime}$ and rev. $5^{\prime}$-CCATCTTTCCAGCCCCAAGT-3'. Foxp3 1

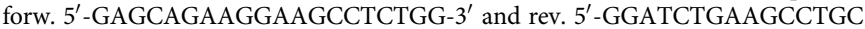
CATGT- $3^{\prime}$. Foxp3 2 forw. $5^{\prime}$-CCTCGGGATGCCTTTGTGAT- $3^{\prime}$ and rev. $5^{\prime}$-ACAGGGCTCATGAGAAACCA-3'.

Statistical analysis. For animal experiments to determine group size needed for adequate statistical power, power analysis employing the program $G^{*}$ power was performed using preliminary data sets. Mice of the indicated genotype were assigned at random to groups. Mouse studies were performed in a blinded fashion. Results are shown as mean \pm s.e.m. with the number of independent experiments. Statistical significance was calculated using unpaired Student's $t$-test; ${ }^{*} P \leq 0.05$, ${ }^{* *} P \leq 0.001$ and ${ }^{* *} P \leq 0.0001$; n.s., not significant. Groups were large enough to fulfill the prerequisite of Student's $t$-test as well as to determine that the variance between groups is similar. The statistical significance of differences between human groups was determined by analysis of variance.

Data availability. The authors declare that all data supporting the findings of this study are available within the article and its Supplementary Information files or from the corresponding author upon reasonable request.

\section{References}

1. Finkelstein, S. D., Sasatomi, E. \& Regueiro, M. Pathologic features of early inflammatory bowel disease. Gastroenterol. Clin. North Am. 31, 133-145 (2002).

2. Monteleone, G. et al. Interleukin 12 is expressed and actively released by Crohn's disease intestinal lamina propria mononuclear cells. Gastroenterology 112, 1169-1178 (1997).

3. Fuss, I. J. et al. Disparate CD4 + lamina propria (LP) lymphokine secretion profiles in inflammatory bowel disease. Crohn's disease LP cells manifest increased secretion of IFN-gamma, whereas ulcerative colitis LP cells manifest increased secretion of IL-5. J. Immunol. 157, 1261-1270 (1996).

4. Park, S. G. et al. T regulatory cells maintain intestinal homeostasis by suppressing gammadelta T cells. Immunity 33, 791-803 (2010).

5. Mizoguchi, A. et al. Cytokine imbalance and autoantibody production in T cell receptor-alpha mutant mice with inflammatory bowel disease. J. Exp. Med. 183, 847-856 (1996).

6. McVay, L. D. et al. Changes in human mucosal gamma delta T cell repertoire and function associated with the disease process in inflammatory bowel disease. Mol. Med. 3, 183-203 (1997).

7. Yeung, M. M. et al. Characterisation of mucosal lymphoid aggregates in ulcerative colitis: immune cell phenotype and TcR-gammadelta expression. Gut 47, 215-227 (2000).

8. Powrie, F., Carlino, J., Leach, M. W., Mauze, S. \& Coffman, R. L. A critical role for transforming growth factor-beta but not interleukin 4 in the suppression of T helper type 1-mediated colitis by CD45RB(low) CD4 + T cells. J. Exp. Med. 183, 2669-2674 (1996).

9. Asseman, C., Mauze, S., Leach, M. W., Coffman, R. L. \& Powrie, F. An essential role for interleukin 10 in the function of regulatory $\mathrm{T}$ cells that inhibit intestinal inflammation. J. Exp. Med. 190, 995-1004 (1999).

10. Mayne, C. G. \& Williams, C. B. Induced and natural regulatory T cells in the development of inflammatory bowel disease. Inflam. Bowel Dis. 19, 1772-1788 (2013).

11. Boden, E. K. \& Snapper, S. B. Regulatory T cells in inflammatory bowel disease. Curr. Opin. Gastroenterol. 24, 733-741 (2008).

12. Liston, A. \& Gray, D. H. Homeostatic control of regulatory T cell diversity. Nat. Rev. Immunol. 14, 154-165 (2014).

13. Barnes, M. J. et al. Commitment to the regulatory $\mathrm{T}$ cell lineage requires CARMA1 in the thymus but not in the periphery. PLoS Biol. 7, e51 (2009).

14. Long, M., Park, S. G., Strickland, I., Hayden, M. S. \& Ghosh, S. Nuclear factor-kappaB modulates regulatory $\mathrm{T}$ cell development by directly regulating expression of Foxp3 transcription factor. Immunity 31, 921-931 (2009).

15. Ruan, Q. et al. Development of Foxp3 $(+)$ regulatory t cells is driven by the c-Rel enhanceosome. Immunity 31, 932-940 (2009).

16. Isomura, I. et al. c-Rel is required for the development of thymic Foxp3 + CD4 regulatory T cells. J. Exp. Med. 206, 3001-3014 (2009).

17. Messina, N. et al. The NF-kappaB transcription factor RelA is required for the tolerogenic function of Foxp3 $(+)$ regulatory T cells. J. Autoimmun. 70, 52-62 (2016).

18. Schuster, M. et al. IkappaB(NS) protein mediates regulatory T cell development via induction of the Foxp3 transcription factor. Immunity 37, 998-1008 (2012).

19. Bours, V. et al. The oncoprotein Bcl-3 directly transactivates through kappa B motifs via association with DNA-binding p50B homodimers. Cell 72, 729-739 (1993).

20. Franzoso, G. et al. The candidate oncoprotein Bcl-3 is an antagonist of p50/NF-kappa B-mediated inhibition. Nature 359, 339-342 (1992).

21. Fujita, T., Nolan, G. P., Liou, H. C., Scott, M. L. \& Baltimore, D. The candidate proto-oncogene bcl-3 encodes a transcriptional coactivator that activates through NF-kappa B p50 homodimers. Genes Dev. 7, 1354-1363 (1993).

22. Palmer, S. \& Chen, Y. H. Bcl-3, a multifaceted modulator of NF-kappaBmediated gene transcription. Immunol. Res. 42, 210-218 (2008).

23. Carmody, R. J., Ruan, Q., Palmer, S., Hilliard, B. \& Chen, Y. H. Negative regulation of toll-like receptor signaling by NF-kappaB p50 ubiquitination blockade. Science 317, 675-678 (2007).

24. Song, L. et al. BCL3 reduces the sterile inflammatory response in pancreatic and biliary tissues. Gastroenterology 150, 499-512 e420 (2016).

25. Schwarz, E. M., Krimpenfort, P., Berns, A. \& Verma, I. M. Immunological defects in mice with a targeted disruption in Bcl-3. Genes Dev. 11, 187-197 (1997).

26. Franzoso, G. et al. Critical roles for the Bcl-3 oncoprotein in T cell-mediated immunity, splenic microarchitecture, and germinal center reactions. Immunity 6, 479-490 (1997).

27. Tang, W. et al. The oncoprotein and transcriptional regulator Bcl-3 governs plasticity and pathogenicity of autoimmune T cells. Immunity 41, 555-566 (2014).

28. O'Carroll, C. et al. Bcl-3 deficiency protects against dextran-sodium sulphateinduced colitis in the mouse. Clin. Exp. Immunol. 173, 332-342 (2013). 
29. Tang, W. et al. The B-cell tumor promoter Bcl-3 suppresses inflammationassociated colon tumorigenesis in epithelial cells. Oncogene 35, 6203-6211 (2016).

30. Hovelmeyer, N. et al. Overexpression of Bcl-3 inhibits the development of marginal zone B cells. Eur. J. Immunol. 44, 545-552 (2014).

31. Powrie, F., Leach, M. W., Mauze, S., Caddle, L. B. \& Coffman, R. L. Phenotypically distinct subsets of CD4 + T cells induce or protect from chronic intestinal inflammation in C. B-17 scid mice. Int. Immunol. 5, 1461-1471 (1993).

32. Stockinger, B., Barthlott, T. \& Kassiotis, G. The concept of space and competition in immune regulation. Immunology 111, 241-247 (2004).

33. Mitchell, T. C. et al. Immunological adjuvants promote activated $\mathrm{T}$ cell survival via induction of Bcl-3. Nat. Immunol. 2, 397-402 (2001).

34. Thornton, A. M. et al. Expression of Helios, an Ikaros transcription factor family member, differentiates thymic-derived from peripherally induced Foxp3 + T regulatory cells. J. Immunol. 184, 3433-3441 (2010).

35. Sha, W. C., Liou, H. C., Tuomanen, E. I. \& Baltimore, D. Targeted disruption of the p50 subunit of NF-kappa B leads to multifocal defects in immune responses. Cell 80, 321-330 (1995).

36. Esparza, E. M. \& Arch, R. H. Glucocorticoid-induced TNF receptor, a costimulatory receptor on naive and activated T cells, uses TNF receptorassociated factor 2 in a novel fashion as an inhibitor of NF-kappa B activation. J. Immunol. 174, 7875-7882 (2005).

37. Wing, K. et al. CTLA-4 control over Foxp3 + regulatory T cell function. Science 322, 271-275 (2008)

38. Franzoso, G. et al. The oncoprotein Bcl-3 can facilitate NF-kappa B-mediated transactivation by removing inhibiting p50 homodimers from select kappa B sites. EMBO J. 12, 3893-3901 (1993).

39. Kerr, L. D. et al. The proto-oncogene bcl-3 encodes an I kappa B protein. Genes Dev. 6, 2352-2363 (1992).

40. Heissmeyer, V., Krappmann, D., Wulczyn, F. G. \& Scheidereit, C. NF-kappaB p105 is a target of IkappaB kinases and controls signal induction of Bcl-3-p50 complexes. EMBO J. 18, 4766-4778 (1999).

41. Kanno, Y., Vahedi, G., Hirahara, K., Singleton, K. \& O’Shea, J. J. Transcriptional and epigenetic control of $\mathrm{T}$ helper cell specification: molecular mechanisms underlying commitment and plasticity. Annu. Rev. Immunol. 30, 707-731 (2012)

42. Wong, D. et al. Extensive characterization of NF-kappaB binding uncovers non-canonical motifs and advances the interpretation of genetic functional traits. Genome Biol. 12, R70 (2011).

43. Wulczyn, F. G., Naumann, M. \& Scheidereit, C. Candidate proto-oncogene bcl-3 encodes a subunit-specific inhibitor of transcription factor NF-kappa B. Nature 358, 597-599 (1992).

44. Naumann, M., Wulczyn, F. G. \& Scheidereit, C. The NF-kappa B precursor p105 and the proto-oncogene product $\mathrm{Bcl}-3$ are I kappa B molecules and control nuclear translocation of NF-kappa B. EMBO J. 12, 213-222 (1993).

45. Xiao, X. et al. GITR subverts Foxp3 $(+)$ Tregs to boost Th9 immunity through regulation of histone acetylation. Nat. Commun. 6, 8266 (2015)

46. Michel, F. et al. Crystal structure of the ankyrin repeat domain of Bcl-3: a unique member of the IkappaB protein family. EMBO J. 20, 6180-6190 (2001).

47. Herrington, F. D. \& Nibbs, R. J. Regulation of the adaptive immune response by the IkappaB family protein Bcl-3. Cells 5, E14 (2016).

48. Hatada, E. N. et al. The ankyrin repeat domains of the NF-kappa B precursor p105 and the protooncogene bcl-3 act as specific inhibitors of NF-kappa B DNA binding. Proc. Natl Acad. Sci. USA 89, 2489-2493 (1992).

49. Inoue, J., Takahara, T., Akizawa, T. \& Hino, O. Bcl-3, a member of the I kappa B proteins, has distinct specificity towards the Rel family of proteins. Oncogene 8, 2067-2073 (1993)

50. Nolan, G. P. et al. The bcl-3 proto-oncogene encodes a nuclear I kappa B-like molecule that preferentially interacts with NF-kappa B p50 and p52 in a phosphorylation-dependent manner. Mol. Cell. Biol. 13, 3557-3566 (1993).

51. Dechend, R. et al. The Bcl-3 oncoprotein acts as a bridging factor between NF-kappaB/Rel and nuclear co-regulators. Oncogene 18, 3316-3323 (1999).

52. Ruan, Q. et al. The Th17 immune response is controlled by the Rel-RORgamma-RORgamma T transcriptional axis. J. Exp. Med. 208, 2321-2333 (2011).

53. Wessells, J. et al. BCL-3 and NF-kappaB p50 attenuate lipopolysaccharideinduced inflammatory responses in macrophages. J. Biol. Chem. 279, 49995-50003 (2004).
54. Chiba, T., Inoko, H., Kimura, M. \& Sato, T. Role of nuclear IkappaBs in inflammation regulation. Biomol. Concepts 4, 187-196 (2013).

55. Neurath, M. F. et al. The transcription factor T-bet regulates mucosal T cell activation in experimental colitis and Crohn's disease. J. Exp. Med. 195, 1129-1143 (2002).

56. Atreya, R. et al. Blockade of interleukin 6 trans signaling suppresses T-cell resistance against apoptosis in chronic intestinal inflammation: evidence in crohn disease and experimental colitis in vivo. Nat. Med. 6, 583-588 (2000).

57. Lee, P. P. et al. A critical role for Dnmtl and DNA methylation in T cell development, function, and survival. Immunity 15, 763-774 (2001).

58. Heinen, A. P. et al. Improved method to retain cytosolic reporter protein fluorescence while staining for nuclear proteins. Cytometry A 85, 621-627 (2014).

59. Reissig, S., Hackenbruch, C. \& Hovelmeyer, N. Isolation of T cells from the gut Methods Mol. Biol. 1193, 21-25 (2014).

60. Glasmacher, E. et al. A genomic regulatory element that directs assembly and function of immune-specific AP-1-IRF complexes. Science 338, 975-980 (2012).

61. Blecher-Gonen, R. et al. High-throughput chromatin immunoprecipitation for genome-wide mapping of in vivo protein-DNA interactions and epigenomic states. Nat. Protoc. 8, 539-554 (2013).

\section{Acknowledgements}

We thank Petra Adams-Quack, Bettina Kalt and Elena Zurkowski for excellent technical assistance. We thank Linda Koch and Anna-Lisa Schaub for carefully proofreading the manuscript. We thank Kathrin Davari for the final localization studies of Bcl-3 in T cells K.G. is supported by the grant J-50 (IZKF) and B.W. by the DFG grant WE 4656/2-2. N.H. is supported by the DFG grant HO 4440/1-2. A.W. is supported by the DFG grants TRR156 and AW 1600/8-1, and by the EU consortia NeuroKine. A.W. and N.H. are members of the Immunology Center of Excellence Mainz (FZI).

\section{Author contributions}

S.R. conceived the study and performed experiments. N.H. and A.W. conceptualized and supervised the whole project. N.H., A.W., S.R. and E.G. prepared the manuscript. E.G. designed and supervised Bcl-3 molecular assays, including Bcl-3 and NF- $\kappa \mathrm{B}$ expression analysis, immunoprecipitations, localization studies, as well as EMSAs, reporter assays and CHiP experiments. Y.T. was involved in experimental procedures. A.N. performed immunohistochemistry. C.W. performed immunoprecipitations and pulldown experiments. EMSAs and reporter assays in part developed by and/or taken over by C.G or E.G. B.W., M.F.N., J.M.S. and P.R.G. provided human samples. B.W. and K.G. performed RT-PCR and western blotting with human samples. J.M. performed experiments F.T.W. was involved in generating $\mathrm{Bcl}-3^{\mathrm{OE}}$ mice. I.A.M. was involved in correcting the manuscript. All authors discussed results and conclusions and reviewed the manuscript.

\section{Additional information}

Supplementary Information accompanies this paper at http://www.nature.com/ naturecommunications

Competing interests: The authors declare no competing financial interests.

Reprints and permission information is available online at http://npg.nature.com/ reprintsandpermissions/

How to cite this article: Reißig, S et al. Elevated levels of Bcl-3 inhibits Treg development and function resulting in spontaneous colitis. Nat. Commun. 8, 15069 doi: $10.1038 /$ ncomms15069 (2017).

Publisher's note: Springer Nature remains neutral with regard to jurisdictional claims in published maps and institutional affiliations.

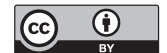

This work is licensed under a Creative Commons Attribution 4.0 International License. The images or other third party material in this article are included in the article's Creative Commons license, unless indicated otherwise in the credit line; if the material is not included under the Creative Commons license, users will need to obtain permission from the license holder to reproduce the material. To view a copy of this license, visit http://creativecommons.org/licenses/by/4.0/

C The Author(s) 2017 